\title{
Reproductive health, fairness, and optimal policies
}

\author{
Johanna Etner ${ }^{1}$, Natacha Raffin ${ }^{1,2}$, Thomas Seegmuller ${ }^{3}$
}

\author{
${ }^{1}$ EconomiX, Université Paris Nanterre, \\ CNRS, Nanterre, France \\ ${ }^{2}$ CREAM, Université Rouen Normandie, \\ Rouen, France \\ ${ }^{3}$ CNRS, EHESS, Centrale Marseille, AMSE, \\ Aix-Marseille University, Marseille, France \\ Correspondence \\ Natacha Raffin, CREAM, Université Rouen \\ Normandie, Rouen 76000, France. \\ Email: natacha.raffin@univ-rouen.fr
}

\begin{abstract}
We consider an overlapping generations economy in which agents differ through their ability to procreate. Ex-ante infertile households may incur health ex-penditure to increase their chances of parenthood. This health heterogeneity generates welfare inequal-ities that deserve to be ruled out. We explore three different criteria of social evaluation in the longrun: the utilitarian approach, the ex-ante egalitarian cri-terion and the ex-post egalitarian one. We propose a set of economic instruments to decentralize each solution. To correct for the externalities and health inequalities, both a preventive (a taxation of capital) and a redistributive policy are required. We show that a more egalitarian allocation is associated with higher productive investment but reduced health expenditure and thus, lower population growth.
\end{abstract}

\section{1 | INTRODUCTION}

The state of human reproductive health has been one important debate in medical sciences in recent years. The issue raised by a bench of papers concerns the natural ability for a couple to have a child since it has been observed that infertility affects around 9\% of procreating-aged couples worldwide (Inhorn \& Patrizio, 2015).

Regarding this question, we draw the reader's attention that it differs from fertility issues generally addressed in the economic literature. Indeed, following the Barro-Becker analysis (1989), a huge literature has developed on the economic determinants of fertility, that is the number of children a household chooses to have. Some papers, among others, have focused on the quality-quantity trade-off to justify the negative relationship between fertility and economic growth; others dealt with the development of a unified growth theory that allows to understand 
the demographic transition (Galor \& Weil, 2000); others are more interested in fertility differentials to better figure out economic inequalities (De la Croix \& Doepke, 2003). In this paper, we study equity in a model with undesired infertility.

Our concern focuses on biological impairments that prevent couples to reproduce, based on relevant measures of human fertility, independently from individual choices. The deterioration of human reproductive health has been widely documented from a functional perspective in the epidemiological literature. Many studies point out the decline in men semen quality since the beginning of the 20th century, the expanding Time To Pregnancy or the prevalence of new female complex reproductive disorders (like endometriosis, ovarian quality, etc.), independent of the age-related natural decline in women fertility. For instance, following the seminal paper by Carlsen, Giwercman, Keiding, and Skakkebk (1992) that gave birth to the famous "falling sperm counts" story, many studies have established a global declining quality of the spermatogenis. Figure 1 illustrates some trends established in the literature, using one specific biomarker for male fertility. As for women reproductive health, there are ongoing research with respect to the use of bio-markers like antral follicular count and antimuëllerian hormone (Nelson, 2013). Meanwhile, a recent epidemiological literature has studied the prevalence of endocrine disorders like polycystic ovarian symptoms (PCOs) or diagnosed endometriosis which are among the main causes of infertility. For instance, March et al. (2010) show that PCOs are diagnosed for around $15 \%$ or more of reproductive-aged women.

All these compelling evidence raise concerns that the reproductive health at a couple level could fall below some threshold levels that could impact fecundity, since those bio-markers and diseases are suitable indicators of chances to parenthood. In addition and crucial to our analysis, these studies that point out a rapid change in human reproductive health cover periods of fast economic development. Hence, we argue that postindustrial societies have created the potential for increasing the exposure to specific lifestyle factors that might impair reproductive health. Among them, one can identify pollution or diet that might contribute to explain the current worldwide infertility and came along with the development process. We may find in the epidemiological literature many studies to support our view and that have long suggested

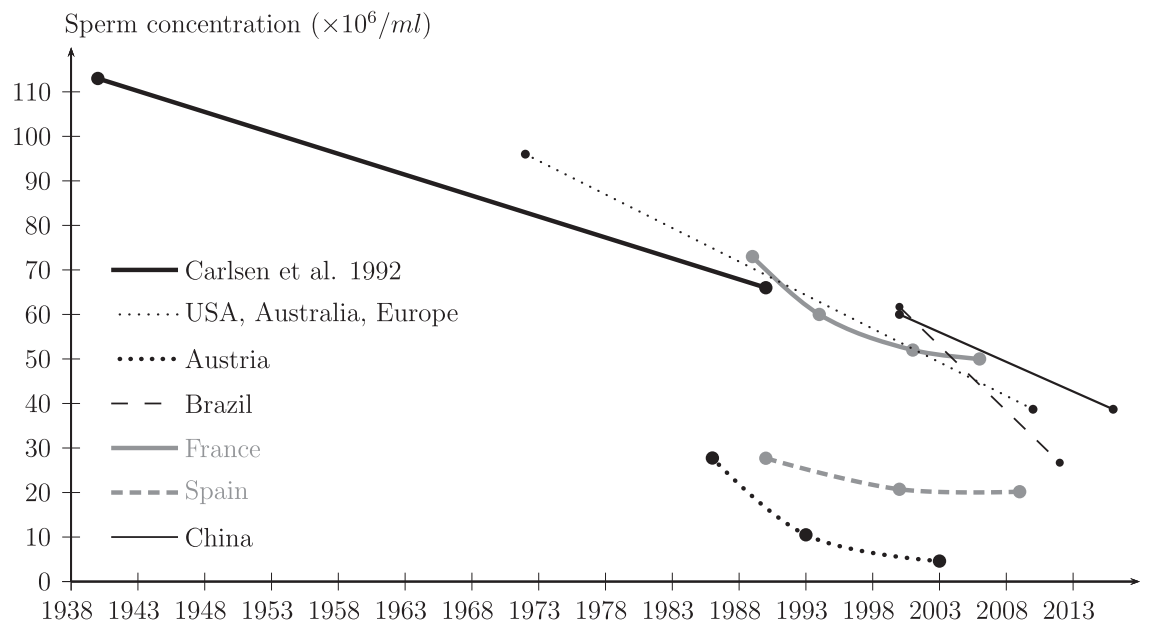

F I G U RE 1 Evolution of sperm concentration. Data from Borges et al. (2015), Carlsen et al. (1992), Huang et al. (2017), Lackner et al. (2005), Levine et al. (2017), Rolland et al. (2013), Romero-Otero et al. (2015) 
adverse effects of exposure to environmental contaminants, such as persistent organic pollutants, on men and women reproductive health. ${ }^{1}$

Moreover, parenthood is a source of well-being and we should be concerned that some couples can not reproduce. ${ }^{2}$ To satisfy their desire of parenthood, some agents may be compelled to use costly medical services like Assisted Reproductive Technology (ART). For instance, since 2000 , ART cycles annually grows by $5 \%-10 \%$ in developed countries (Kupka et al., 2016). This reduced ability to conceive children may be also costly to overcome for the society. As shown by Chambers, Sullivan, Ishihara, Chapman, and Adamson (2009), the use of ARTs represents substantial out-of-pocket health expenses. The estimated cost of a standard in vitro fecundation (IVF) cycle ranges from $28 \%$ of Gross National Income (GNI) per capita in the United States to $10 \%$ of GNI per capita in Japan. Also before any public policy, the gross cost of a standard IVF cycle ranges from 50\% of an individual's annual disposable income in the United States, approximately $20 \%$ in the UK, Scandinavian countries and Australia, to $12 \%$ in Japan.

In our paper, we propose to explore the welfare inequalities induced by a health heterogeneity since infertility entails a loss of utility. What matters to us is the unfair feature of such a health heterogeneity because agents are not totally responsible for their reproductive health status. This is true if we think, for instance, to intra-utero pollution exposure or living conditions during childhood. We consider an overlapping generations model in which the development process generates an externality as a form of a health heterogeneity: two types of households coexist within one generation, the fertile and infertile households. Moreover, ex-ante infertile couples incur health treatments to increase their chances of parenthood. Hence, the laissez-faire economy is characterized by several externalities: beyond the oligodendrocytes (OLG)-induced inefficiency, the accumulation of capital slackens population growth meanwhile health care spending create positive external effects on the demographic dynamics.

We aim at discussing the efficient way to correct these externalities in the long term. At first, we consider the usual utilitarian social objective, but in contrast to Renström and Spataro (2019), we do not restrict our attention to a welfarist approach, even though they enrich it with a critical level of utility. Indeed, in the utilitarian case, health inequalities still prevail and we can be concerned that the utility of the fertile is larger than the utility of the ex-ante infertile. Because heterogeneity is not the result of any actions held by agents but rather due to circumstances (let us refer for instance to pollution exposure), we also explore alternative criteria of social evaluation according to Fleurbaey (2008), Ponthière (2016), or Fleurbaey, Leroux, Pestieau, Ponthière, and Zuber (2018). More precisely, we consider an inequality averse social planner who either maximizes the expected long-run well-being of the worst-off (ex-ante egalitarian social criteria) or maximizes the long-run realized well-being of the worst-off (ex-post egalitarian social criteria).

Our results drive us to formulate some policy recommendations. To rule out inefficiencies, capital accumulation should be taxed. We argue that this preventive policy should be favored

\footnotetext{
${ }^{1}$ See for instance Mendola, Messer, and Rappazzo (2008), Recio-Vega, Ocampo-Gomez, Borja-Aburto, Moran-Martinez, and Cebrian-Garcia (2008), Perry et al. (2011), Martenies and Perry (2013), Slama et al. (2013), Mehrpour, Karrari, Zamani, Tsatsakis, and Abdollahi (2014), Zhou et al. (2014), Chiu et al. (2015), Bolden, Rochester, Schultz, and Kwiatkowski (2017), or Sifakis, Androutsopoulos, Tsatsakis, and Spandidos (2017).

${ }^{2}$ The distress associated with subfertility or treatments of infertility causes induces substantial sociopsychological costs, like a severe degradation of self-esteem, syndromes of depression, loss of gender identity, self-assessed social pressure from families, friendships, and so forth (Greil, 1997; Moura-Ramos, Gameiro, Canavarro, \& Soares, 2012).
} 
and should come along with redistribution among heterogeneous households. Again, with regard to our example of pollution, we claim that fighting against pollution is a relevant public action since it controls the source of an altered reproductive health. Intuitively, health inequalities should be corrected through higher investments in fertility treatments. This is surely true if one considers only health concerns. However, as soon as a general equilibrium framework that also takes into account the trade-off between health care, productive investment and consumption is adopted, the decision maker is lead to tax health care expenditure. To compensate the Infertile for the loss of utility they experience, the public decision maker augments their life-time consumption levels.

Considering equal opportunities implies to reduce more health expenditure meanwhile to increase more physical capital compared with the utilitarian optimum. This trade-off between health expenditure and capital implies that more equality drives less population growth.

Finally, our paper adds a contribution to the economic literature that investigates the prevalence of childlessness within western economies, be it voluntarily or involuntarily (Aaronson, Lange, \& Mazumder, 2014; Baudin, de la Croix, \& Gobbi, 2015, 2019; Gobbi, 2013) although we focus our analysis on the involuntarily motive for childlessness and the desire to have offspring which might be unsatisfied. To that extent, our paper is closer to Momota (2016) who also introduces heterogeneity among households due to the ability of having children. However, his concern is drastically different to ours: he is interested in the effects of exogenous population growth on the level of capital accumulation, whereas in our framework, population growth is endogenous. The paper also refers to the literature that explores fairness issues in the presence of health inequalities. While most papers deals with life expectancy (Fleurbaey, Leroux, \& Ponthière, 2014, 2016; Ponthière, 2016), we consider an alternative health dimension which is nonetheless fundamental, that is the reproductive health status.

The paper is organized as follows: Following Section 1, Section 2 presents the set-up of the model and Section 3 the laissez-faire equilibrium. Section 4 investigates the utilitarian optimal stationary solution and presents a set of optimal tools to decentralize it. Section 5 discusses alternative criteria of social evaluation that take into account the prevailing health inequalities. Finally, Section 6 concludes. Technical proofs are relegated to Appendices.

\section{2 | THE MODEL}

Let us consider a two-period overlapping generations model. During the first period, adulthood, households work, consume, save and procreate and, as in Hung-Ju (2018), we consider an exogenous fertility rate. The ability to procreate is already given. For instance, we may refer to the effect of pollution during pregnancy time or childhood. At each date $t$, two types of household coexist depending on their ability to conceive children: we distinguish fertile households (denoted by superscript $F$ ) and infertile households (denoted by superscript $I$ ). Even though individuals' choices of consumption do not directly interfere with their health determinants, in case of infertility, households can spend on medical treatments to improve their ability to reproduce. These fertility treatments include different types of procedures, going from basic hormonal remedies to much more sophisticated methods of ART treatments like in vitro fertilization (IVF). They obviously aim at augmenting the chances of parenthood so that, with a probability $q$, initially infertile couples may eventually have children. During the second period of life, households retire and consume their savings. 


\section{1 | Demography}

The proportion of fertile households within the population is denoted by $\pi_{t}$ (the proportion of infertile ones equals $\left(1-\pi_{t}\right)$ ). This probability to be fertile is randomly distributed among the population. The total number of children born at date $t$ equals the number of children of fertile households $\left(N_{t} n \pi_{t}\right)$ plus the number of children of successfully treated infertile households $\left(N_{t} n\left(1-\pi_{t}\right) q_{t}\right)$, where $n$ denotes the exogenous number of children each couple may have and $N_{t}$ is the size of the adult generation at date $t$. Hence, the adult population, that is, the labor force evolves overtime according to

$$
N_{t+1}=N_{t} \times n \times\left[\pi_{t}+\left(1-\pi_{t}\right) q_{t}\right]
$$

\subsection{Households}

During the first period of life, households $i$ derive utility from current consumption $\left(c_{t}^{i}\right)$ as well as parenthood $(\tilde{v}): U\left(c_{t}^{i}, \tilde{v}\right)$. When old, they derive utility from future consumption $\left(d_{t+1}^{i}\right): u\left(d_{t+1}^{i}\right)$. They do not choose the number of children they have, fertility is exogenous, although they might suffer from not being able to procreate. We consider a state-dependent utility function since households face a health risk linked to their ability to conceive, $\tilde{v}$ can take two values: $v$ with probability $q_{t}$ and 0 with probability $1-q_{t}$. Their preferences are represented by an expected utility function:

$$
E U^{i}\left(c_{t}^{i}, d_{t}^{i}, v\right)= \begin{cases}U\left(c_{t}^{F}, v\right)+\delta u\left(d_{t+1}^{F}\right), & \text { if } i=F, \\ q_{t} U\left(c_{t}^{I}, v\right)+\left(1-q_{t}\right) U\left(c_{t}^{I}, 0\right)+\delta u\left(d_{t+1}^{I}\right), & \text { if } i=I .\end{cases}
$$

Following Aaronson et al. (2014), Baudin et al. (2015, 2019), we consider the following specifications. On the one hand, the utility function is given by $U\left(c_{t}, \tilde{v}\right)=u\left(c_{t}\right)+\tilde{v}$, with $u\left(z_{t}\right)=\ln z_{t}{ }^{3}$ On the other hand, the probability for a treatment to be successful writes: $q\left(x_{t}\right)=\frac{a x_{t}}{1+x_{t}}$, with $a \leqslant 1$ and $x_{t}$ denotes the level of health care expenditure. The parameter $a$ merely accounts for the efficiency of the available medical technology or, equivalently, the level of scientific medical knowledge.

Let us now present the budget constraints faced by households. For ease of presentation, we right now introduce a set of policy instruments that will be useful in the following. During adulthood, each household is endowed with one unit of labor inelastically offered to firms for which it receives the prevailing competitive wage, $w_{t}{ }^{4}$ In addition, it might benefit from a differentiated lump-sum transfer, $T_{t}^{i}$. The net total income can be shared among current consumption, saving, $s_{t}^{i}$, and possibly for infertile households, health care. During retirement, each couple consumes the net income which equals the revenue from saving minus a transfer, $\theta_{t+1}$. For both types of household, the first period budget constraint can be expressed as follows:

\footnotetext{
${ }^{3}$ We assume so far that parenthood does not impact the marginal utility of consumption. We discuss this assumption in Section 4.

${ }^{4}$ Notice that here the health status does not affect productivity at work. Also, to keep the analysis as simple as possible, we do not introduce rearing cost of children. Since the number of offspring is assumed to be constant, enriching the analysis with such a cost will not drastically alter our analysis.
} 


$$
\begin{gathered}
c_{t}^{F}+s_{t}^{F}=w_{t}+T_{t}^{F}, \\
c_{t}^{I}+s_{t}^{I}+\left(1-\sigma_{t}\right) x_{t}=w_{t}+T_{t}^{I},
\end{gathered}
$$

where $\sigma_{t}$ is the health policy instrument. The second period budget constraints write:

$$
d_{t+1}^{i}=R_{t+1} s_{t}^{i}-\theta_{t+1}, \quad \text { for } i=F, I
$$

where we assume a complete depreciation of capital and we define $R_{t+1} \equiv\left(1-\rho_{t+1}\right) r_{t+1}$, with $\rho_{t}$ a proportional tax on capital income.

\section{3 | Government}

At each date $t$, the government provides transfers to the young generation and can subsidy health expenditure thanks to a tax on capital and a lump-sum tax on the old. The balanced budget constraint of the government is given by:

$$
N_{t-1}\left[\theta_{t}+\rho_{t} r_{t}\left(\pi_{t-1} S_{t-1}^{F}+\left(1-\pi_{t-1}\right) s_{t-1}^{I}\right)\right]=N_{t}\left(\pi_{t} T_{t}^{F}+\left(1-\pi_{t}\right) T_{t}^{I}\right)+N_{t} \sigma_{t}\left(1-\pi_{t}\right) x_{t}
$$

\section{$2.4 \mid$ Firms}

One good is produced using both physical capital, $K_{t}$, and labor, $L_{t}$. We can immediately define per capita variables: $y_{t}=Y_{t} / L_{t}, k_{t}=K_{t} / L_{t}$. Again, to obtain tractable results, we assume a fairly standard Cobb-Douglas production function:

$$
y_{t}=k_{t}^{\alpha}
$$

with $0<\alpha<1 / 2$. Being given the price of capital $\left(r_{t}\right)$ and the competitive wage $\left(w_{t}\right)$, the optimization program of firms yields:

$$
\begin{gathered}
r_{t}=\alpha k_{t}^{\alpha-1}, \\
w_{t}=(1-\alpha) k_{t}^{\alpha} .
\end{gathered}
$$

\section{5 | Reproductive health}

As documented in Section 1, the development process generates a harmful externality that negatively affects the probability of being fertile. Since GDP per capita is a well-established measure of development and it increases with capital per capita, we state that $\pi_{t}=\pi\left(k_{t}\right)$ and $\pi^{\prime}(k) \leqslant 0$ so that, as one economy develops, the natural reproductive health declines. We explicit in further details our hypothesis about this endogenous probability of being fertile in Assumption 1:

Assumption 1. We assume that $\pi$ is sufficiently close to 1 and $\epsilon_{\pi} \equiv \frac{\pi^{\prime}(k) k}{\pi(k)}$ is close to 0 with $\pi^{\prime}(k) \leqslant 0 \leqslant \pi^{\prime \prime}(k), \pi(0)=\pi_{0}>\pi(+\infty)>0$. 
This assumption means that the chances of parenthood are weakly decreasing with the stock of capital and sufficiently close to 1 . If we interpret the relationship between $\pi$ and $k$ as the effect of pollution on couples reproductive health, Assumption 1 seems in accordance with the empirical literature.

Within this framework, we can now analyze the static choices made by households and then investigate the long-run behavior of this economy.

\section{3 | THE LAISSEZ-FAIRE ECONOMY}

This section defines the inter-temporal equilibrium in the laissez-faire economy, the levels of policy instruments, $T_{t}^{i}, \sigma_{t}, \theta_{t+1}$, and $\rho_{t+1}$, being set to zero. The equilibrium, given the variables from the previous period, can be defined by a wage rate $w_{t}$ and a gross rate of return $R_{t}$, aggregate variables $K_{t}, L_{t}$, and $Y_{t}$ and individuals variables, $c_{t}^{F}, s_{t}^{F}, c_{t}^{I}, s_{t}^{I}$, and $x_{t}$.

\section{1 | Households' choices}

Households maximize their expected utility (2) under the budget constraints (3)-(5) and a positivity constraint, $x_{t} \geqslant 0$. We derive from the first-order conditions, the trade-off between young and old consumptions and the trade-off between health and consumption for the Infertile:

$$
\begin{gathered}
\frac{1}{c_{t}^{i}}=\frac{\delta R_{t+1}}{d_{t+1}^{i}}, \quad \text { for } i=F, I, \\
\frac{1}{c_{t}^{I}} \geqslant \frac{a v}{\left(1+x_{t}\right)^{2}}, \quad \text { with an equality if } x_{t}>0 .
\end{gathered}
$$

Fertile households do not spend on health care and we can easily deduce their optimal level of saving, which is increasing with labor income:

$$
s_{t}^{F}=\frac{\delta}{1+\delta} w_{t} \equiv s^{F}\left(k_{t}\right)
$$

with $s^{F^{\prime}}\left(k_{t}\right)>0$. As for the Infertile, let us note that if $x_{t}=0$, then

$$
s_{t}^{F} \leqslant \frac{\delta}{a v}
$$

This inequality implies that the loss of utility from a low level of consumption dominates the potential welfare gain associated with an improved reproductive health. Hence, since the utility function defined over consumption is concave, this inequality is verified all the more that consumption levels are initially low. We can state that for low incomes, it is more likely that households do not invest in fertility treatments. In that configuration, $s_{t}^{I}=s_{t}^{F}$. On the contrary, if Equation (13) is not satisfied, $x_{t}>0$ and, using Equation (12), we get the optimal saving and health expenditure for infertile households: 


$$
\begin{gathered}
s_{t}^{I}=s^{F}\left(k_{t}\right)-\frac{\delta}{1+\delta} x_{t}, \\
\left(1+x_{t}\right)^{2}=\frac{a v}{\delta} s_{t}^{I} .
\end{gathered}
$$

Solving the system (14)-(15), we deduce the expression of $x_{t}$ and $s_{t}^{I}$ as functions of $k_{t}$ :

$$
x_{t} \equiv x\left(k_{t}\right)=\sqrt{\frac{a v(1-\alpha)}{1+\delta} k_{t}^{\alpha}-1+A^{2}}-A, \quad \text { with } A \equiv 1+\frac{a v}{2(1+\delta)},
$$

and

$$
s_{t}^{I} \equiv s^{I}\left(k_{t}\right)=\frac{\delta\left(1+x\left(k_{t}\right)\right)^{2}}{a v}
$$

where $x^{\prime}\left(k_{t}\right)>0$ and $s^{I^{\prime}}\left(k_{t}\right)>0$.

\section{2 | Labor market}

On the labor market at date $t$, the supply of labor $N_{t}$ being inelastic and the demand $L_{t}$ being the solution to Equation (9), we get that:

$$
L_{t}=N_{t}=N_{t-1} \times n \times\left[\pi\left(k_{t-1}\right)+\left(1-\pi\left(k_{t-1}\right)\right) q\left(x\left(k_{t-1}\right)\right)\right] .
$$

\section{3 | Capital market}

The clearing condition on the capital market entails that the supply of saving by the young equals the capital used by firms:

$$
K_{t+1}=N_{t}\left[\pi\left(k_{t}\right) s^{F}\left(k_{t}\right)+\left(1-\pi\left(k_{t}\right)\right) s^{I}\left(k_{t}\right)\right] .
$$

Using Equation (18), we derive the dynamics of capital-labor ratio:

$$
k_{t+1}=\frac{\pi\left(k_{t}\right) s^{F}\left(k_{t}\right)+\left(1-\pi\left(k_{t}\right)\right) s^{I}\left(k_{t}\right)}{n \Gamma\left(x\left(k_{t}\right), k_{t}\right)},
$$

where $\Gamma\left(x\left(k_{t}\right), k_{t}\right)=\left[\pi\left(k_{t}\right)+\left(1-\pi\left(k_{t}\right)\right) q\left(x\left(k_{t}\right)\right)\right]$ and $n \Gamma\left(x\left(k_{t}\right), k_{t}\right)$ is the endogenous growth factor of the population size of generations. The accumulation of physical capital induces two opposite effects on population growth: a negative direct effect through the increase in the number of infertile households and a positive indirect effect through health expenditure. When the negative effect dominates, physical capital accumulation entails a negative dilution effect ${ }^{5}$, otherwise a positive one. In addition, physical capital accumulation impacts global saving, through three channels: (a) it affects the distribution of infertile and fertile households within the population; (b) it increases savings for each type of household; (c) it triggers more health

${ }^{5}$ Recall that the dilution effect corresponds to a decrease of per capita variables following an increase in the labor force or, equivalently, in the population growth. 
expenditure and thus involves an eviction effect on the Infertile's saving. The global dynamics of the economy depends on the magnitude of each mechanism.

Given $k_{0}=K_{0} / L_{0} \geqslant 0$, the inter-temporal equilibrium is a sequence $\left\{k_{t}\right\}$ that satisfies condition (20) for all $t \geqslant 0$. A steady state with $x>0$, if it exists, is a solution $k$ that solves the above dynamic Equation (20) evaluated at the steady state, so that $k_{t}=k_{t+1}=k$. The existence and uniqueness of such a steady state is characterized in the following proposition.

Proposition 1. Under Assumption 1 and if $v$ sufficiently large, so that

$$
v>\tilde{v} \equiv\left[\frac{1+\delta}{a(1-\alpha)}\right] \times\left[\frac{(1-\alpha) \delta}{(1+\delta) n \pi(0)}\right]^{-\frac{\alpha}{1-\alpha}},
$$

there exists a unique steady state, $k$, such that health expenditure is strictly positive $(x>0)$.

\section{Proof. See Appendix A.}

We show that, in the long term, the economy reaches a stationary state in which infertile households do spend on fertility treatments if the benefit of parenthood is large enough. Indeed, investing in ARTs to augment the chances of parenthood is costly and induces an eviction effect on saving. Nevertheless, by increasing the share of procreating households, the demographic growth is boosted.

\section{4 | THE CLASSICAL UTILITARIAN WELFARE ANALYSIS}

Our model is characterized by several inefficiencies that we identify now. First, accumulating physical capital induces a negative externality as it increases the probability to be infertile and decreases the one to be fertile. This implies a lower utility for each generation. But beyond this, physical capital creates an additional externality because more physical capital means less population growth. Simultaneously, since households may spend on health care, there exists a third externality, because health expenditure also influence the population growth factor. Finally, because of the overlapping generations, the intergenerational allocation at the equilibrium can be suboptimal. Of course, all these externalities are relevant at an inter-temporal equilibrium as well as at a steady state. In this set-up, we aim at exploring what would be a first-best optimal allocation. To that end, we propose a welfare analysis using a classical utilitarian criterion of social evaluation and we characterize the optimal solution. Then, we provide some policy recommendations to correct the inefficiencies and discuss the nature of the economic policy.

\section{1 | The utilitarian social optimum}

The utilitarian social planner maximizes a Millian social welfare objective that takes into account the average expected utility, ${ }^{6} S W^{U}$. In this context of endogenous population, we assume that she does not grant any particular weight to the overall size of the population but rather the average level of

${ }^{6}$ See Blackorby, Bossert, and Donaldson (2005) for a discussion of the social welfare criteria when the population is endogenous. 
utility is maximized. To derive clear cut results and compare them with the laissez-faire economy, we focus our analysis on the stationary solution. To comply with her goal, the social planner chooses the optimal levels of consumption $\left(c^{F}, c^{I}, d^{F}, d^{I}\right)$, health expenditures $(x)$, and physical capital $(k)$, under the two constraints of resources and positivity for health care expenditure. The program of the utilitarian central planner can thus be written as follows:

$$
\begin{cases}\max _{c^{F}, c^{I}, d^{F}, d^{I}, x, k,} & S W^{U} \equiv \pi(k)\left[\ln c^{F}+\delta \ln d^{F}+v\right] \\ & +(1-\pi(k))\left[\ln c^{I}+\delta \ln d^{I}+\frac{a x}{1+x} v\right], \\ \text { s.t. } & k^{\alpha} \geqslant \pi(k) c^{F}+(1-\pi(k))\left(c^{I}+x\right) \\ & +\frac{\pi(k) d^{F}+(1-\pi(k)) d^{I}}{n \Gamma(x, k)}+n k \Gamma(x, k) \\ & x \geqslant 0 .\end{cases}
$$

First of all, at the optimum, expected marginal utilities of consumption are equalized and thus consumption levels should be equalized among heterogeneous agents, $c^{F}=c^{I}=c^{*}, d^{F}=d^{I}=d^{*}{ }^{7}$ Then we already depart from the laissez-faire choices of consumption and we confirm that a policy should be implemented to reach the optimal utilitarian solution. Second, we derive the optimal trade-off between young and old consumption over the life-cycle:

$$
\delta c^{*}=\frac{d^{*}}{n \Gamma\left(x^{*}, k^{*}\right)}
$$

The marginal rate of substitution between young and old consumption is equal to the optimal population growth factor, $n \Gamma\left(x^{*}, k^{*}\right){ }^{8}$ Third, we consider the trade-off between consumption and health:

$$
\frac{a v}{\left(1+x^{*}\right)^{2}}+\frac{\delta a}{\left(1+x^{*}\right)^{2} \Gamma\left(x^{*}, k^{*}\right)}=\frac{1}{c^{*}}+\frac{n k^{*} a}{c^{*}\left(1+x^{*}\right)^{2}}-\frac{\mu^{*}}{1-\pi\left(k^{*}\right)},
$$

where $\mu$ is the Lagrange multiplier associated to the positivity constraint on $x$. There exists an interior optimal solution for health expenditure when the marginal social welfare gain from investing in health equals the marginal social welfare loss. On the one hand, the marginal social welfare gain consists in a pure utility gain from parenthood plus a reallocation of resources within generations, through the reduced weight granted to old households' consumption. On the other hand, the marginal social welfare loss is the foregone consumption added to the required increase in the productive investment. Finally, we deduce the trade-off between generations, which is given by

$$
\begin{aligned}
\alpha\left(k^{*}\right)^{\alpha-1}= & n \Gamma\left(x^{*}, k^{*}\right)-\pi^{\prime}\left(k^{*}\right) x^{*} \\
& +c^{*} \pi^{\prime}\left(k^{*}\right)\left[\left(1-\frac{a x^{*}}{1+x^{*}}\right)\left(\frac{n k^{*}}{c^{*}}-\frac{\delta}{\Gamma\left(x^{*}, k^{*}\right)}-v\right)\right] .
\end{aligned}
$$

\footnotetext{
${ }^{7}$ Superscripts * indicate the utilitarian optimal solution. See Appendix B for more details.

${ }^{8}$ Notice that our results are robust to alternative specification of separable utility functions, like CES between young and old consumption: $U\left(c_{t}, d_{t}, v\right)=\frac{\left(c_{t}\right)^{1-\epsilon}}{1-\epsilon}+v+\delta \frac{\left(d_{t+1}\right)^{1-\epsilon}}{1-\epsilon}$.
} 
This condition is in fact a modified golden rule. If the probability to be fertile were constant, then we would have obtained a standard golden rule, except for the presence of the growth factor. As soon as the capital externality occurs, additional and potentially opposite effects arise. Keeping in mind that investment and production are related, more capital means less population, lowering the cost of productive investment. Nevertheless, more capital induces more infertile households and thus lowers the social welfare. This last negative effect mitigates the former incentives to accumulate physical capital.

Using these arbitrages, we can also study the existence and the properties of the utilitarian optimal allocation. In particular, although we do not know whether the optimal level of health expenditure is higher than the laissez-faire one, we can show that it should be strictly positive. This is stated in Proposition 2 below:

Proposition 2. Under Assumption 1 and $v$ sufficiently large, there exists a unique optimal allocation $\left(x^{*}, k^{*}\right)$ with $x^{*}>0$.

\section{Proof. See Appendix C.}

As discussed previously, we could consider the case where parenthood affects the marginal utility of consumption. Let us now consider the utility function for a fertile and infertile agent respectively, as follows:

$$
E U^{i}\left(c_{t}^{i}, d_{t}^{i}, v\right)= \begin{cases}U\left(c_{t}^{F}, v\right)+\delta u\left(d_{t+1}^{F}\right), & \text { if } i=F, \\ q_{t} U\left(c_{t}^{I}, v\right)+\left(1-q_{t}\right) U\left(c_{t}^{I}, 0\right)+\delta u\left(d_{t+1}^{I}\right), & \text { if } i=I,\end{cases}
$$

where $U_{1}\left(c_{t}^{i}, v\right)>0, U_{11}\left(c_{t}^{i}, v\right) \leqslant 0$ and $u\left(d_{t}^{i}\right)$ is increasing and concave in $d_{t}$. We deduce from Appendix D that, at the optimum, $d^{I *}=d^{F *}=d^{*}$. We also show that

$$
q(x) U_{1}\left(c^{I}, v\right)+(1-q(x)) U_{1}\left(c^{I}, 0\right)=U_{1}\left(c^{F}, v\right)
$$

Consequently, we have

$$
U_{1}\left(c^{F}, v\right)-U_{1}\left(c^{I}, v\right) \gtreqless 0 \Leftrightarrow U_{1}\left(c^{I}, 0\right)-U_{1}\left(c^{I}, v\right) \gtreqless 0
$$

Or,

$$
c^{F} \gtreqless c^{I} \Leftrightarrow U_{12} \gtreqless 0
$$

In the case of a state-dependent utility, the role played by correlation aversion/loving (first introduced by Richard, 1975; see also Eeckhoudt, Rey, \& Schlesinger, 2007, for multivariate risk preferences) is crucial. Correlation loving corresponds, in health economics, to the complementarity between wealth and health while correlation aversion refers to a subsitutability between the two. ${ }^{9}$ In our set-up, if $U_{12}<0$, the marginal utility of consumption is higher in the

${ }^{9}$ Correlation aversion implies that an individual prefers to disaggregate fixed reductions in health and consumption. Notice that correlation aversion - that is an individual prefers to disaggregate harms -in the case of one attribute means that she is risk averse. 
case of no parenthood: individuals are correlation averse. In that case, the central planner gives more to the Infertile to obtain a higher level of welfare. If $U_{12}>0$, the marginal utility of consumption is higher in the case of parenthood: individuals are correlation prone. To increase welfare, the central planner gives more to the Fertile. Of course, if $U_{12}=0$, levels of consumption are identical for both types of household. To our knowledge, there is no empirical support and/or theoretical justification for one particular assumption. Nevertheless, Attema, L'haridon, and van de Kuilen (2019) recently find empirical evidence of correlation aversion for gains in health and wealth. Following their work, our results would not change significantly.

Once we have described the optimal utilitarian solution, we naturally wonder how to reach it in the market economy. To do so, we derive again the decentralized optimal choices for both types of household once policy instruments are enforced and we compare them with the utilitarian optimal solution. We can then discuss the optimal design of the public policy to be implemented, according to the preferences of the social planner.

\section{2 | The utilitarian optimal policy}

In an OLG framework, we need first to correct the inefficient level of capital. To reach the golden rule, a proportional tax on capital, $\rho$, is implemented. Moreover, to ensure the budget is balanced at each period, lump-sum transfers to the old, $\theta$, are enforced. Second, considering a reproductive health issue introduces heterogeneity among households and displays an external effect on population growth. Therefore, two adding instruments are required to restore optimality: a distortionary subsidy on health expenditure $(\sigma)$ and a lump-sum transfer toward the young $\left(T^{i}\right)$. Notice that the capital externality that shapes the distribution of the Fertile and the Infertile within the population is corrected through the appropriate distortionary tax on capital. The following proposition summarizes our results.

Proposition 3. Consider that Assumption 1 holds, $\delta$ small and $v$ sufficiently large, the utilitarian social optimum can be decentralized by means of the following instruments:

(i) A tax on capital income, $\rho^{*}=1-\frac{n \Gamma^{*}}{\alpha\left(k^{*}\right)^{\alpha-1}} \in(0,1)$;

(ii) A tax on health expenditure, $\sigma^{*}<0$, such that $\frac{\sigma^{*}}{1-\sigma^{*}}=\frac{1}{v}\left(\frac{\delta}{\Gamma^{*}}-\frac{n k^{*}}{c^{*}}\right)<0$;

(iii) Differentiated lump-sum transfers between the Fertile and the Infertile, $T^{F *}$ and $T^{I *}$, satisfying $T^{F^{*}}=0$ and $T^{I *}=\left(1-\sigma^{*}\right) x^{*}>0$;

(iv) A positive lump-sum tax on the old, $\theta^{*}>0$, to balance the government's budget.

\section{Proof. See Appendix E.}

The positiveness of $\theta^{*}$ involves a taxation of old households' consumption. This generates fiscal resources meanwhile it incites young households to save more. This capital accumulation is the source of the externality that should be corrected. Hence, the government implements a proportional tax on capital income to ensure the achievement of the "adjusted" golden rule (see Equation (23)). In addition, this capital accumulation generates more consumption and allows infertile households to afford for more and more fertility treatments. It reinforces the heterogeneity between the two groups. To enforce the optimal level of health expenditure, we show that a tax on health care is required. Nevertheless, to guarantee that consumption are identical among the two types of households, positive transfers toward the young should be 
differentiated. This result might be at first sight surprising and counter-intuitive; However, let us re-examine the infertile households' budget constraint: $c^{I}+\left(1-\sigma-T^{I} / x\right) x+s^{I}=w$. Taking into account the redistribution effect through $T^{I}$, the health policy design can be summarized by a unique variable $t(x) \equiv \sigma+T^{I} / x$. At the utilitarian optimum, we easily see that $t(x)>0 .{ }^{10}$ Overall, infertile couples are well subsidized by the government.

To sum-up, the optimal public policy design includes redistribution and a tax on physical capital that should be interpreted as a preventive policy tool. But a public health policy that reduces the cost of ARTs is not relevant to reach the optimum. For instance, if we follow-up with our example of pollution, the authorities should favor the reduction of polluting emissions that alter couples reproductive health and ensure that infertile households can derive sufficiently high expected utility all over their life-cycle, through both consumption and parenthood.

\section{3 | Discussion}

Using a classical utilitarian criterion, the instruments to decentralize the social optimum allow to reduce inequalities among the two social groups-the Fertile and the Infertile-through the equalization of consumptions and the reduction of the capital externality. Nonetheless, the optimal policy does not eradicate the source of health inequality but may compensate for it by subsidizing the Infertile and enforcing an identical level of consumption. We can still be concerned with such an approach since the utility of the Fertile is larger than the expected utility of the Infertile. In addition, if we consider that the risk of fertility agents are exposed to is not the consequence of any action, but rather due to circumstances, then this health heterogeneity appears to be unfair. It is typically the case of pollution exposure for which agents can not be blamed a priori. In the following sections, we explore alternative criteria of social evaluation for which the social planner exhibits inequality aversion. We then assess the optimal design of the public policy that should be implemented, in comparison with the utilitarian solution.

\section{5 | INEQUALITY AVERSION CRITERIA}

The capital externality generates a distribution on the two types of households and this creates different outcome prospects. Even if, for the social observer, the ability to reproduce is viewed as random, the fact that it is antecedent to the decision process suggests that it should be considered as circumstances. According to the "compensation principle" (see Fleurbaey, 2008; Ponthière, 2016), such type of inequalities, due to circumstances, should be eliminated as much as possible. In addition, in our set-up, the random consequence of fertility treatments generates an other type of heterogeneity among the Infertile. Then, we distinguish two sources of health inequalities that deserve to be handled. To do so, we rely on two approaches developed in the economic literature: the ex-ante inequality aversion and the ex-post inequality aversion. In the first case, the social planner focuses on the differences between social groups defined by the same set of circumstances (here, the Fertile and the Infertile) while, in the second case, she considers the unequal outcome among individuals who exert the same effort (here the Infertile). These two approaches seem to be relevant in the case of this twofold dimension of health inequality.

\footnotetext{
${ }^{10}$ Since $\sigma<0$ and $T^{I}>0, t(x)$ is strictly decreasing and there exists $\hat{x}=-T^{I} / \sigma>0$ such that $t(x)>0$ for $x<\hat{x}$ and $t(x)<0$ for $x>\widehat{x}$.
} 


\section{1 | Ex-ante egalitarian criterion}

Let us first consider a social planner who adopts an ex-ante egalitarian criterion of the social welfare evaluation. This social objective implies to select the allocation that maximizes the expected lifetime well-being of the worst-off social group, the ex-ante infertile households. The social welfare function is:

$$
S W^{E} \equiv \min \left\{E U^{F}\left(c^{F}, d^{F}, v\right), E U^{I}\left(c^{I}, d^{I}, v\right)\right\}
$$

where $E U^{F}\left(c^{F}, d^{F}, v\right)=\ln c^{F}+\delta \ln d^{F}+v$ and $E U^{I}\left(c^{I}, d^{I}, v\right)=\ln c^{I}+\delta \ln d^{I}+\frac{a x}{1+x} v$.

It is possible to rewrite this problem as the maximization of the expected utility of the exante Infertile, conditionally on the resource constraint of the economy, the positivity constraint on $x$ and, conditionally on the egalitarian constraint so that ex-ante infertile households are not worse-off than fertile households.

$$
\begin{cases}\max _{c^{F}, c^{I}, d^{F}, d^{I}, x, k} & \ln c^{I}+\delta \ln d^{I}+\frac{a x}{1+x} v, \\ \text { s.t. } & k^{\alpha} \geqslant \pi(k) c^{F}+(1-\pi(k))\left(c^{I}+x\right) \\ & +\frac{\pi(k) d^{F}+(1-\pi(k)) d^{I}}{n \Gamma(x, k)}+n k \Gamma(x, k) \\ & x \geqslant 0, \\ & \ln c^{F}+\delta \ln d^{F}+v=\ln c^{I}+\delta \ln d^{I}+\frac{a x}{1+x} v .\end{cases}
$$

As usual, at the optimum, ${ }^{11}$ we can write the trade-off between young and old consumption over the life-cycle:

$$
\delta c^{i E}=\frac{d^{i E}}{n \Gamma\left(x^{E}, k^{E}\right)} \quad \text { for } i=F, I .
$$

Like in the utilitarian solution, the marginal rate of substitution between life-time consumptions is equal to the optimal population growth factor, $n \Gamma\left(x^{E}, k^{E}\right)$. Nevertheless, contrary to the utilitarian optimal solution, consumption levels are not equalized among heterogeneous households. Indeed, we can show that:

$$
c^{F E}=\frac{\xi^{E}}{1-\xi^{E}} \frac{1-\pi\left(k^{E}\right)}{\pi\left(k^{E}\right)} c^{I E} \quad \text { and } \quad d^{F E}=\frac{\xi^{E}}{1-\xi^{E}} \frac{1-\pi\left(k^{E}\right)}{\pi\left(k^{E}\right)} d^{I E},
$$

with $\xi^{E}$ the Lagrange multiplier associated to the egalitarian constraint and $\xi^{E}<\pi\left(k^{E}\right)$. Consequently, we deduce that $c^{F E}<c^{I E}$ and $d^{F E}<d^{I E}$ and thus the situation is indeed reversed compared to the laissez-faire economy.

Second, we obtain a similar trade-off between consumption and health compared with the utilitarian one:

$$
\frac{a v}{\left(1+x^{E}\right)^{2}}+\frac{\delta a}{\left(1+x^{E}\right)^{2} \Gamma\left(x^{E}, k^{E}\right)} \frac{1-\pi\left(k^{E}\right)}{1-\xi^{E}}=\frac{1}{c^{I E}}+\frac{n k^{E} a}{c^{I E}\left(1+x^{E}\right)^{2}}-\frac{\mu^{E}}{1-\xi^{E}}
$$

\footnotetext{
${ }^{11}$ Superscripts ${ }^{E}$ indicate the ex-ante egalitarian solution. See Appendix F for more details.
} 
with $\mu^{E}$ the Lagrange multiplier associated to the positivity constraint on $x$. Finally, the tradeoff between generations yields an alternative modified golden rule

$$
\begin{aligned}
\alpha\left(k^{E}\right)^{\alpha-1}= & n \Gamma\left(x^{E}, k^{E}\right)-\pi^{\prime}\left(k^{E}\right) x^{E} \\
& +c^{I E} \pi^{\prime}\left(k^{E}\right)\left(1-\frac{a x^{E}}{1+x^{E}}\right)\left[\frac{n k^{E}}{c^{I E}}-\frac{\delta}{\Gamma\left(x^{E}, k^{E}\right)}\left(\frac{1-\pi\left(k^{E}\right)}{1-\xi^{E}}\right)\right] \\
& +c^{I E} \pi^{\prime}\left(k^{E}\right)(1+\delta)\left(\frac{\xi^{E}}{1-\xi^{E}} \frac{1-\pi\left(k^{E}\right)}{\pi\left(k^{E}\right)}-1\right) .
\end{aligned}
$$

Under this criterion, the weight granted to the Fertile $\left(\xi^{E}\right)$ is lower compared to the utilitarian case $\left(\pi\left(k^{E}\right)\right)$. By adapting the proof of Proposition 2, we can easily show that $\mu^{E}=0$ and thus an interior solution exists, $x^{E}>0$. Therefore, like in the utilitarian case, there is a unique pair $\left(x^{E}, k^{E}\right)$ that characterizes the ex-ante egalitarian equilibrium. The consequences on the optimal level of health expenditure and physical capital are given in the following proposition.

Proposition 4. Consider that Assumption 1 holds and $v$ sufficiently large. Under the ex-ante egalitarian social criterion, the optimal level of health expenditure satisfies $0<x^{E}<x^{*}$ and the optimal stock of capital $k^{E}>k^{*}$.

Proof. See Appendix F.

A risk of fertility treatment still prevails because $q(x)$ is strictly lower than one. Thus, the expected utility of parenthood is always smaller for infertile couples, $q(x) v<v$. Therefore, to ensure the equality of welfare for all households, the social planner allocates more life-cycle consumption to the Infertile and less to the Fertile. If $\xi^{E}$ were equal to $\pi\left(k^{E}\right)$, consumption levels would be identical. Since $\xi^{E}<\pi\left(k^{E}\right)$, it comes that the solutions differ so that $c^{I E}>c^{*}$ and $d^{I E}>d^{*}$. Moreover, since the weight granted to the Infertile is larger, it comes that the aggregate consumption is larger compared to the utilitarian case. To finance this augmented aggregate consumption, the social planner invests more in productive capital, detrimental to health expenditure.

We can now discuss the design of the public policy required to decentralize the ex-ante egalitarian social optimum. ${ }^{12}$ The expression of the proportional tax on capital is similar to the utilitarian one and one can also implement a positive lump-sum transfer to the infertile young only, $T^{F E}=0$ and $T^{I E}>0$. From the previous analysis, we can directly deduce that the tax on health expenditures is larger: $-\sigma\left(x^{*}, k^{*}\right)<-\sigma\left(x^{E}, k^{E}\right)$. Since fertility treatments are not entirely efficient, the most relevant public action consists in a more generous redistributive policy, besides the taxation of the capital, that is the source of infertility.

\section{2 | Ex-post egalitarian criterion}

Let us now consider an ex-post egalitarian social planner who allocates the resources according to the level of the realized well-being of the worst-off. Recall that in our framework, having children

${ }^{12}$ See Appendix G. 
does not entail any cost since we focus on the loss of utility induced by infertility and fertility is exogenous. We assume that $v$ is sufficiently large to ensure that the worst-off group is composed of agents who have invested in fertility treatment but for whom it was unsuccessful. Say differently, the cost of child bearing is relatively not significant compared with the benefit of having children (Moura-Ramos et al., 2012). Ex-ante Infertile households are identical before the success of fertility treatments is revealed and make similar decisions $\left(c^{I}, s^{I}, x\right)$. Once the treatment is realized, there are two types of infertile households because some of them succeed $(i=I F)$ while some others do not $(i=I I)$. The social planner corrects the treatment-induced inequality between the two types of infertile households in terms of well-being, focusing on the second period consumption $\left(d^{I F}\right.$ and $\left.d^{I I}\right)$. Ex-post, there are a priori three types of household in the economy. The realized utility of fertile households writes: $U^{F}\left(c^{F}, d^{F}, v\right)=\ln c^{F}+\delta \ln d^{F}+v$; the one of lucky Infertile $U^{I F}\left(c^{I}, d^{I F}, v\right)=$ $\ln c^{I}+\delta \ln d^{I F}+v$; and, the one of unlucky Infertile $U^{I I}\left(c^{I}, d^{I I}\right)=\ln c^{I}+\delta \ln d^{I I}$.

Taking into account the realized utilities of the three types of household, the social welfare function writes:

$$
S W^{P} \equiv \min \left\{U^{F}\left(c^{F}, d^{F}, v\right), U^{I F}\left(c^{I}, d^{I F}, v\right), U^{I I}\left(c^{I}, d^{I I}, v\right)\right\}
$$

Following the ex-post egalitarian criterion, the objective of the social planner is to maximize the utility of ex-post infertile households who have invested in health but for whom the treatment was unsuccessful. We can write the optimization program conditionally on the resource constraint of the economy, the positivity constraint on $x$ and the egalitarian constraints such that unlucky infertile households are not worse-off than lucky infertile and fertile households:

$$
\begin{cases}\max _{c^{F}, c^{I}, d^{F}, d^{I F}, d^{I I}, x, k} & \ln c^{I}+\delta \ln d^{I I}, \\ \text { s.t. } & k^{\alpha} \geqslant \pi(k) c^{F}+(1-\pi(k))\left[c^{I}+x\right] \\ & +\frac{\pi(k) d^{F}+(1-\pi(k))\left[q(x) d^{I F}+(1-q(x)) d^{I I}\right]}{n \Gamma(x, k)}+n k \Gamma(x, k) \\ & x \geqslant 0, \\ & \ln c^{F}+\delta \ln d^{F}+v=\ln c^{I}+\delta \ln d^{I I}, \\ & \ln c^{I}+\delta \ln d^{I F}+v=\ln c^{I}+\delta \ln d^{I I},\end{cases}
$$

As usual, at the ex-post egalitarian optimum, we obtain the trade-off between consumptions over the life-cycle: ${ }^{13}$

$$
\begin{gathered}
\delta c^{F P}=\frac{d^{F P}}{n \Gamma\left(x^{P}, k^{P}\right)}, \\
\delta c^{I P}=\frac{q\left(x^{P}\right) d^{I F P}+\left(1-q\left(x^{P}\right)\right) d^{I I P}}{n \Gamma\left(x^{P}, k^{P}\right)} .
\end{gathered}
$$

In addition, when the social planner is averse to ex-post inequalities, we can establish that consumption levels for old unlucky infertile households are larger than the ones of fertile and further on old lucky infertile couples: $d^{I I P}>d^{F P}>d^{I F P}$. We also find that $c^{I P}>c^{F P}$.

\footnotetext{
${ }^{13}$ Superscripts ${ }^{P}$ indicate the ex-post egalitarian solution. See Appendix $\mathrm{H}$ for more details.
} 
Second, we derive the trade-off between consumption and health expenditure

$$
\begin{aligned}
& \frac{\lambda^{P} a\left(1-\pi\left(k^{P}\right)\right)}{\left(1+x^{P}\right)^{2}}\left(\frac{d^{I I P}}{n \Gamma\left(x^{P}, k^{P}\right)}-\frac{d^{I F P}}{n \Gamma\left(x^{P}, k^{P}\right)}\right)+\delta \frac{a\left(1-\pi\left(k^{P}\right)\right)}{\left(1+x^{P}\right)^{2} \Gamma\left(x^{P}, k^{P}\right)} \\
& =\frac{n k^{P} \lambda^{P} a\left(1-\pi\left(k^{P}\right)\right)}{\left(1+x^{P}\right)^{2}}+\lambda^{P}\left(1-\pi\left(k^{P}\right)\right)-\mu^{P} .
\end{aligned}
$$

where $\lambda^{P}$ and $\mu^{P}$ are the Lagrange multipliers associated to the resources and positivity constraints.

Finally, we obtain the trade-off between generations

$$
\begin{aligned}
\alpha\left(k^{P}\right)^{\alpha-1}= & n \Gamma\left(x^{P}, k^{P}\right)+\pi^{\prime}\left(k^{P}\right)\left[c^{F P}-c^{I P}-x^{P}\right]+n k^{P} \pi^{\prime}\left(k^{P}\right)\left(1-\frac{a x^{P}}{1+x^{P}}\right) \\
& -\left(\pi\left(k^{P}\right) c^{F P}+\left(1-\pi\left(k^{P}\right)\right) c^{I P}\right) \pi^{\prime}\left(k^{P}\right)\left(1-\frac{a x^{P}}{1+x^{P}}\right) \frac{\delta}{\Gamma\left(x^{P}, k^{P}\right)} \\
& -\delta\left(c^{I P}-c^{F P}\right) \pi^{\prime}\left(k^{P}\right)\left(1-\frac{a x^{P}}{1+x^{P}}\right) .
\end{aligned}
$$

Proposition 5. Consider that Assumption 1 holds, $v$ sufficiently large and $\delta$ sufficiently small. Under the ex-post egalitarian social criterion, the optimal level of health expenditure satisfies $x^{P}=0<x^{E}<x^{*}$ and the optimal stock of capital $k^{P}>k^{E}>k^{*}$.

\section{Proof. See Appendix H.}

This criterion involves that the social planner rules out ex-post inequalities among infertile households. Because the treatment is not perfectly efficient, the social planner chooses no treatment in fertility $\left(x^{P}=0\right)$. Hence, ex-post, there is only one type of infertile households, $i=I I$. There is no longer households of type $i=I F$ because $q(0)=0$. In addition, to reduce inequalities between fertile and infertile households, the social planner distributes resources toward the Infertile's consumption all over the life-cycle. To finance this increased consumption, she needs to invest more in physical capital. Since there is no health expenditure, she invests more in productive capital compared to the previous criteria. Notice that if the worst-off group would be the lucky Infertile (for instance due to costs of child bearing), it does not drastically modify our analysis, since the utility of the three types of household is equalized at the ex-post egalitarian optimum.

Let us turn now to the design of the public policy to decentralize the ex-post egalitarian social optimum. ${ }^{14}$ We can state that the tax on fertility treatment is sufficiently large to incite households not to spend on health care. The expression of the other instruments are similar to the previous cases.

\section{3 | Discussion}

At the laissez-faire, households do not enjoy the same level of utility. This social situation can be viewed as unfair. As seen in the previous section, at the utilitarian optimum, these inequalities are not considered, even if consumptions are equalized among households.

\footnotetext{
${ }^{14}$ See Appendix I.
} 
As far as the social planner is concerned with the reduction of inequalities, we adopt welfare criteria that aim to reduce these utility differentials. In the ex-ante approach, the two social groups - the Fertile and the ex-ante Infertile-have the same expected utility before one knows whether the treatment is successful. After the realization of the risk, three types of households with three different realized levels of utility prevail. In the ex-post approach, we take into account the realization of the utilities of the three types of household. Only two social groups-the Fertile and the ex-post Infertile-persist in the second period, but they have the same realized utility. Even though we do not discuss the choice of the egalitarian criteria to be adopted, one can be interested in considering equal opportunities and compare them with the utilitarian optimum. We have established that whatever the egalitarian criterion we use, health expenditure are reduced and investment in physical capital is increased compared with the utilitarian optimum. This also means that more equality implies less population growth and that there exists a trade-off between egalitarism among individuals and population growth.

Intuitively, health inequalities should be corrected through higher investments in fertility treatments. This could be true if one considers only health concerns. We show that this is no more true as soon as general equilibrium framework that also takes into account the trade-off between health expenditure, productive investment, and consumption is adopted.

\section{6 | CONCLUDING REMARKS}

Based on epidemiological evidence, we assume that the development process impacts negatively fertility. We analyze the implications of such a feature considering an OLG economy where ex-ante infertile households may incur health expenditure to increase their chances of parenthood. We compare three long-run optimal allocations, depending on the criteria of social evaluation adopted by the planner. We claim that when the social planner does not exhibit any aversion to inequality, the optimal level of health expenditure is the highest one. When she displays inequality aversion, optimal health expenditure diminishes and is equal to zero when she focuses on the realized well-being of the worst-off social group. On the contrary, the utilitarian optimal level of capital is the lowest one and the ex-post egalitarian one is the largest. Then, we determine the optimal policy to decentralize each allocation. We underscore that to correct for the prevailing externality and the health inequality it induces, it is necessary to implement both preventive and redistributive policies, to globally subsidy mostly harmed agents within the economy. More precisely, the tax on health expenditure is a crucial tool to reduce the heterogeneity and to rule out inequalities. Opposite to public policies implemented in many countries which consist in subsidizing ARTs, we argue that to reduce inequalities, it is more appropriate to enforce redistribution and prevention. For instance, if infertility comes from pollution exposure, a fair health policy could be a taxation of polluting emissions. Our strong conclusions could be mitigated if we consider income heterogeneity besides health heterogeneity. In this case, we may justify a positive subsidize to health expenditure that comes along with a preventive and redistributive policy. This paves the way to future research.

\section{ACKNOWLEDGMENTS}

We would like to thank participants to the Conferences Dyniper 2016, SURED 2016, PET 2018, and EAERE 2018 and ASSET 2018 for their helpful comments. This paper benefits from the 


\section{ORCID}

\section{Natacha Raffin (D) http://orcid.org/0000-0001-7279-4119}

\section{REFERENCES}

Aaronson, D., Lange, F., \& Mazumder, B. (2014). Fertility transition along the extensive and the intensive margins? American Economic Review, 104, 1-25.

Attema, A., L'haridon, O., \& van de Kuilen, G. (2019). Measuring multivariate risk preferences in the health domain. Journal of Health Economics, 64, 15-24.

Barro, R., \& Becker, G. (1989). Fertility choice in a model of economic growth. Econometrica, 57, 481-501.

Baudin, T., de la Croix, D., \& Gobbi, P. E. (2015). Fertility and childlessness in the United States. American Economic Review, 105, 1852-1882.

Baudin, T., de la Croix, D., \& Gobbi, P. (2019). Endogenous childlessness and stages of development. Journal of the European Economic Association, 18, 83-133.

Blackorby, C., Bossert, W., \& Donaldson, D. (2005). Population issues in social choice theory, welfare economics, and ethics. Cambridge: Cambridge University Press.

Bolden, A. L., Rochester, J. R., Schultz, K., \& Kwiatkowski, C. F. (2017). Polycyclic aromatic hydrocarbons and female reproductive health: A scoping review. Reproductive Toxicology, 73, 61-74.

Borges, E., SouzaSetti, A., Paes de Almeida Ferreira Braga, D., de Cassia Savio Figueira, R., \& Laconelli, A. (2015). Decline in semen quality among infertile men in Brazil during the past 10 years. International Brazilian Journal of Urology, 41, 757-763.

Carlsen, E., Giwercman, A., Keiding, N., \& Skakkebk, N. (1992). Evidence for decreasing quality of semen quality during past 50 years. British Medical Journal, 305, 609-613.

Chambers, G. M., Sullivan, E. A., Ishihara, O., Chapman, M. G., \& Adamson, G. D. (2009). The economic impact of assisted reproductive technology: A review of selected developed countries. Fertility and Sterility, 91, 2281-2294.

Chiu, Y. H., Afeiche, M. C., Gaskins, A. J., Williams, P. L., Tanrikut, C., Hauser, R., \& Chavarro, J. E. (2015). Fruit and vegetable intake and their pesticide residues in relation to semen quality among men from a fertility clinic. Human Reproduction, 30, 1352-1341.

De la Croix, D., \& Doepke, M. (2003). Inequality and growth: Why differential fertility matters. American Economic Review, 93, 1091-1113.

Eeckhoudt, L., Rey, B., \& Schlesinger, H. (2007). A good sign for multivariate risk taking. Management Science, 53, 117-124.

Fleurbaey, M. (2008). Fairness, responsibility and welfare. New York, NY: Oxford University Press.

Fleurbaey, M., Leroux, M. L., \& Ponthière, G. (2014). Compensating the dead. Journal of Mathematical Economics, 51, 28-41.

Fleurbaey, M., Leroux, M. L., Pestieau, P., \& Ponthière, G. (2016). Fair retirement under risky lifetime. International Economic Review, 57, 177-210.

Fleurbaey, M., Leroux, M. L., Pestieau, P., Ponthière, G., \& Zuber, S. (2018). Premature deaths, accidental bequests and fairness (Mimeo).

Galor, O., \& Weil, D. (2000). Population, technology and growth: From Malthusian stagnation to the demographic transition and beyond. American Economic Review, 90, 806-828.

Gobbi, P. E. (2013). A model of voluntary childlessness. Journal of Population Economics, 26, 963-982.

Greil, A. (1997). Infertility and psychological distress: A critical review of the literature. Social Science and Medicine, 45, 1697-1704.

Huang, C., Li, B., Xu, K., Liu, D., Hu, J., Yang, Y., \& Zhu, W. (2017). Decline in semen quality among 30,636 young Chinese men from 2001 to 2015. Fertility and sterility, 107, 83-88.

Hung-Ju, C. (2018). Fertility, retirement age, and pay-as-you-go pensions. Journal of Public Economic Theory, 20, 944-961.

Inhorn, M., \& Patrizio, P. (2015). Infertility around the globe: New thinking on gender, reproductive technologies and global movements in the 21st century. Human Reproduction Update, 21, 411-426. 
Kupka, M., D'Hooghe, T., Ferraretti, A., de Mouzon, J., Erb, K., Castilla, J., \& Goossens, V. (2016). Assisted reproductive technology in Europe, 2011: Results generated from European registers by ESHRE. Human Reproduction, 31, 233-248.

Lackner, J., Schatzl, G., Waldhör, T., Resch, K., Kratzik, C., \& Marberger, M. (2005). Constant decline in sperm concentration in infertile males in an urban population: Experience over 18 years. Fertility and Sterility, 84, $1657-1661$.

Levine, H., Jørgensen, N., Martino-Andrade, A., Mendiola, J., Weksler-Derri, D., Mindlis, I., \& Swan, S. (2017). Temporal trends in sperm count: A systematic review and meta-regression analysis. Human Reproduction Update, 23, 646-659.

March, W. A., Moore, V. M., Willson, K. J., Phillips, D. I., Norman, R. J., \& Davies, M. J. (2010). The prevalence of polycystic ovary syndrome in a community sample assessed under contrasting diagnostic criteria. Human Reproduction, 25, 544-551.

Martenies, S. E., \& Perry, M. J. (2013). Environmental and occupational pesticide exposure and human sperm parameters: A systematic review. Toxicology, 307, 66-73.

Mehrpour, O., Karrari, P., Zamani, N., Tsatsakis, A., \& Abdollahi, M. (2014). Occupational exposure to pesticides and consequences on male semen and fertility: A review. Toxicology Letters, 230, 146-156.

Mendola, P., Messer, L. C., \& Rappazzo, K. (2008). Science linking environmental contaminant exposures with fertility and reproductive health impacts in the adult female. Fertility and Sterility, 89, 81-94.

Momota, A. (2016). Intensive and extensive margins of fertility, capital accumulation, and economic welfare. Journal of Public Economics, 133, 90-110.

Moura-Ramos, M., Gameiro, S., Canavarro, M. C., \& Soares, I. (2012). Assessing infertility stress: Re-examining the factor structure of the fertility problem inventory. Human Reproduction, 27, 496-505.

Nelson, S. (2013). Biomarkers of ovarian response: Current and future applications. Fertility and Sterility, 99, 963-969.

Perry, M., Venners, S. A., Chen, X., Liu, X., Tang, G., Xing, H., \& Xu, X. (2011). Organophosphorous pesticide exposures and sperm quality. Reproductive Toxicology, 31, 75-79.

Ponthière, G. (2016). Pollution, unequal lifetimes and fairness. Mathematical Social Sciences, 82, 49-64.

Recio-Vega, R., Ocampo-Gomez, G., Borja-Aburto, V. H., Moran-Martinez, J., \& Cebrian-Garcia, M. E. (2008). Organophosphorus pesticide exposure decreases sperm quality: Association between sperm parameters and urinary pesticide levels. Journal of Applied Toxicology, 28, 674-680.

Renström, T., \& Spataro, L. (2019). Population growth: A pure welfarist approach. Journal of Public Economic Theory, 21, 135-166.

Richard, S. (1975). Multivariate risk aversion, utility independence and separable utility functions. Management Science, 22(1), 12-21.

Rolland, M., LeMoal, J., Wagner, V., Royère, D., \& De Mouzon, J. (2013). Decline in semen concentration and morphology in a sample of 26609 men close to general population between 1989 and 2005 in France. Human Reproduction, 28, 462-470.

Romero-Otero, J., Medina-Polo, J., Garcia-Gomez, B., Lora-Pablos, D., Duarte-Ojeda, J., Garcia-Gonzalez, L., \& Rodiguez-Antolin, A. (2015). Semen quality assessment in fertile men in madrid during the last 3 decades. Urology, 85, 1333-1338.

Sifakis, S., Androutsopoulos, V. P., Tsatsakis, A. M., \& Spandidos, D. A. (2017). Human exposure to endocrine disrupting chemicals: Effects on the male and female reproductive systems. Environmental Toxicology and Pharmacology, 51, 56-70.

Slama, R., Bottagisi, S., Solansky, I., Lepeule, J., Giorgis-Allemand, L., \& Sram, R. (2013). Short-term impact of atmospheric pollution on fecundability. Epidemiology, 24, 871-879.

Zhou, N., Cui, Z., Yang, S., Han, X., Chen, G., Zhou, Z., \& Cao, J. (2014). Air pollution and decreased semen quality: A comparative study of Chongqing urban and rural areas. Environmental Pollution, 187, 145-152. 


\section{APPENDIX A: PROOF OF PROPOSITION 1}

Let us consider the regime in which $x_{t}=0$. If a solution exists, then condition (13) should be satisfied. This implies that:

$$
k_{t} \leqslant\left[\frac{1+\delta}{a v(1-\alpha)}\right]^{\frac{1}{\alpha}} \equiv \tilde{k} .
$$

When $x_{t}=0$ and using (20), total saving are given by

$$
k_{t+1}=\frac{(1-\alpha) \delta k_{t}^{\alpha}}{(1+\delta) n \pi\left(k_{t}\right)}
$$

The steady state is defined as a fixed point such that $k_{t+1}=k_{t}=k$ and is a solution if:

$$
k=\frac{(1-\alpha) \delta k^{\alpha}}{(1+\delta) n \pi(k)}
$$

We can easily see that the RHS(k) of the Equation (A3) has the following properties: $R H S(0)=0$ and $\lim _{k \rightarrow+\infty} R H S(k)=+\infty$. Then, $k$ cannot be a solution if $R H S(\tilde{k})>\tilde{k}$. Since, $\pi$ is a decreasing function of $k$, this is satisfied under the following sufficient condition:

$$
\frac{(1-\alpha) \delta}{(1+\delta) n}>\pi(0)\left[\frac{1+\delta}{a v(1-\alpha)}\right]^{\frac{1-\alpha}{\alpha}} .
$$

This is true for a sufficiently large value of $v$ :

$$
v>\tilde{v} \equiv\left[\frac{1+\delta}{a(1-\alpha)}\right] \times\left[\frac{(1-\alpha) \delta}{(1+\delta) n \pi(0)}\right]^{-\frac{\alpha}{1-\alpha}} .
$$

Let us now consider the regime in which $x_{t}>0$. Putting (12), (16), and (17) into (20), we have

$$
k_{t+1}=\frac{\frac{\delta}{1+\delta}(1-\alpha) k_{t}^{\alpha}-\left(1-\pi\left(k_{t}\right)\right) \frac{\delta}{1+\delta} x\left(k_{t}\right)}{n\left[\pi\left(k_{t}\right)+\left(1-\pi\left(k_{t}\right) q\left(x\left(k_{t}\right)\right)\right)\right]} \equiv g\left(k_{t}\right) .
$$

It immediately comes that

$$
k_{t+1}=g\left(k_{t}\right)<\frac{\frac{\delta}{1+\delta}(1-\alpha) k_{t}^{\alpha}}{n \pi\left(k_{t}\right)} .
$$

Since $\frac{g\left(k_{t}\right)}{k_{t}}<\frac{\frac{\delta}{1+\delta}(1-\alpha) k_{t}^{\alpha-1}}{n \pi\left(k_{t}\right)}$, we deduce that $\lim _{k_{t} \rightarrow+\infty} \frac{g\left(k_{t}\right)}{k_{t}}=0$ and there exists a steady state, $k$, such that $x>0$. We can easily show that this steady state is unique. 


\section{APPENDIX B: THE OPTIMAL PROGRAM}

To solve the optimal program, let us write the Lagrangian as:

$$
\begin{aligned}
\mathcal{L}= & \pi(k)\left[\ln c^{F}+\delta \ln d^{F}+v\right]+(1-\pi(k))\left[\ln c^{I}+\delta \ln d^{I}+\frac{a x}{1+x} v\right] \\
& +\lambda\left[k^{\alpha}-\pi(k) c^{F}-(1-\pi(k))\left(c^{I}+x\right)-\frac{\pi(k) d^{F}+(1-\pi(k)) d^{I}}{n \Gamma(x, k)}-n k \Gamma(x, k)\right] \\
& +\mu x .
\end{aligned}
$$

We obtain the following first-order conditions:

$$
\begin{gathered}
\frac{\partial \mathcal{L}}{\partial c^{i}}=0 \Leftrightarrow \frac{1}{c^{i}}=\lambda, \quad i=F, I, \\
\frac{\partial \mathcal{L}}{\partial d^{i}}=0 \Leftrightarrow \frac{\delta n \Gamma(x, k)}{d^{i}}=\lambda, \quad i=F, I, \\
\frac{\partial \mathcal{L}}{\partial x}=\frac{(1-\pi(k)) a v}{(1+x)^{2}}+\lambda \Gamma_{x}(x, k)\left\{\frac{\left[\pi(k) d^{F}+(1-\pi(k)) d^{I}\right]}{n \Gamma(x, k)^{2}}-n k\right\} \\
-\lambda(1-\pi(k))+\mu=0, \\
\frac{\partial \mathcal{L}}{\partial k}=\pi^{\prime}(k)\left[\ln c^{F}+\delta \ln d^{F}+v-\ln c^{I}-\delta \ln d^{I}-\frac{a x}{1+x} v\right] \\
+\lambda\left[\alpha k^{\alpha-1}-n \Gamma(x, k)-n k \Gamma_{k}(x, k)\right]-\lambda \pi^{\prime}(k)\left(c^{F}-\left(c^{I}+x\right)\right) \\
-\lambda\left[\frac{\pi^{\prime}(k)\left(d^{F}-d^{I}\right) \Gamma(x, k)-\Gamma_{k}(x, k)\left[\pi(k) d^{F}+(1-\pi(k)) d^{I}\right]}{n \Gamma(x, k)^{2}}\right]=0,
\end{gathered}
$$

where

$$
\begin{gathered}
\Gamma_{x}(x, k)=(1-\pi(k)) \frac{a}{(1+x)^{2}}>0 \\
\Gamma_{k}(x, k)=\pi^{\prime}(k)\left(1-\frac{a x}{1+x}\right)<0
\end{gathered}
$$

and with complementary slackness:

$$
\begin{gathered}
k^{\alpha} \geqslant \pi(k) c^{F}+\left(1-\pi(k)\left(c^{I}+x\right)+\frac{\pi(k) d^{F}+\left(1-\pi(k) d^{I}\right)}{n \Gamma(x, k)}\right) \\
+n k \Gamma(x, k), \quad \lambda \geqslant 0, \\
\quad \mu x=0, \quad \mu \geqslant 0 .
\end{gathered}
$$




\section{APPENDIX C: PROOF OF PROPOSITION 2}

\section{C1 Existence}

If $x^{*}=0$, we have $\Gamma(0, k)=\pi(k), \Gamma_{x}(0, k)=a(1-\pi(k))$ and $\Gamma_{k}(0, k)=\pi^{\prime}(k)$. Using (21)-(23), an allocation with $x^{*}=0$ is defined by:

$$
\begin{gathered}
\alpha k^{\alpha-1}-n \pi(k)=c^{*} \pi^{\prime}(k)\left[-v-\frac{\delta}{\pi(k)}+\frac{n k}{c^{*}}\right], \\
k^{\alpha}=(1+\delta) c^{*}+n k \pi(k), \\
a v-\frac{1}{c^{*}}+\frac{a \delta}{\pi(k)}-\frac{n a k}{c^{*}}+\frac{\mu}{1-\pi(k)}=0 .
\end{gathered}
$$

From (C2), we define $c^{*}$ as a function of $k$, such that $c^{*}=\frac{k^{\alpha}-\pi(k) n k}{(1+\delta)} \equiv c(k)$. Then using (C1) and (C3), we obtain the following system:

$$
\begin{gathered}
\alpha k^{\alpha-1}-n \pi(k)-\pi^{\prime}(k) n k=-c(k) \pi^{\prime}(k)\left[v+\frac{\delta}{\pi(k)}\right] \\
\frac{\mu}{1-\pi(k)}=\frac{1}{c(k)}+\frac{a}{c(k)}\left[\frac{\alpha k^{\alpha-1}-n \pi(k)}{\pi^{\prime}(k)}\right]
\end{gathered}
$$

Let us consider Equation (C5). We see that $\mu^{*}>0$ if and only if:

$$
\epsilon_{\pi}<-a k \frac{\left[\alpha k^{\alpha-1}-n \pi(k)\right]}{\pi(k)}
$$

We also notice that $(\mathrm{C} 4)$ rewrites:

$$
\frac{\left[\alpha k^{\alpha-1}-n \pi(k)\right] k}{\pi(k)}=c(k) \epsilon_{\pi}\left[\frac{n k}{c(k)}-v-\frac{\delta}{\pi(k)}\right] .
$$

Using (C7), the inequality (C6) reduces to:

$$
v<\frac{1}{a c(k)}+\frac{n k}{c(k)}-\frac{\delta}{\pi(k)}
$$

From (C7), we also deduce that $\alpha k^{\alpha-1}$ is close to $n \pi(k)$ when $\epsilon_{\pi}$ is close to 0 . This implies that both $k$ and $c(k)$ have positive and finite values. Therefore, the inequality (C8) is violated for $v$ high enough, which means that $x^{*}=0$ is not possible.

Using (21), the system of Equations (22), (23), and (B7) with $x^{*}>0$ and $\mu^{*}=0$, satisfied by such an allocation, can be written:

$$
c^{*} \pi^{\prime}(k)\left[\left(1-\frac{a x}{1+x}\right)\left(\frac{n k}{c^{*}}-\frac{\delta}{\Gamma(x, k)}-v\right)\right]-\pi^{\prime}(k) x=\alpha k^{\alpha-1}-n \Gamma(x, k),
$$




$$
\begin{gathered}
\frac{\delta}{\Gamma(x, k)}-\frac{n k}{c^{*}}+v=\frac{(1+x)^{2}}{a c^{*}}, \\
(1+\delta) c^{*}+(1-\pi(k)) x+n \Gamma(x, k) k=k^{\alpha} .
\end{gathered}
$$

From (C9), we deduce:

$$
c^{*}=\frac{1}{1+\delta}\left[k^{\alpha}-(1-\pi(k)) x-n \Gamma(x, k) k\right] \equiv c(x, k)
$$

Using this equation, the system becomes:

$$
c(x, k) \pi^{\prime}(k)\left[\left(1-\frac{a x}{1+x}\right)\left(\frac{n k}{c(x, k)}-\frac{\delta}{\Gamma(x, k)}-v\right)-\frac{x}{c(x, k)}\right]=\alpha k^{\alpha-1}-n \Gamma(x, k)
$$

and

$$
c(x, k)\left[\frac{\delta}{\Gamma(x, k)}+v-\frac{n k}{c(x, k)}\right]=\frac{(1+x)^{2}}{a} .
$$

An optimal allocation is a solution $\left(x^{*}, k^{*}\right)$ to the system (C13) and (C14). Now, substituting (C14) into (C13), we get:

$$
G(x, k) \equiv \alpha k^{\alpha-1}-n \Gamma(x, k)+\frac{\pi^{\prime}(k)}{a}\left[1+2 x+x^{2}(1-a)\right]=0
$$

It implicitly defines $x$ as a function of $k$, that is $x=x(k)$, if $G_{x} \equiv \partial G / \partial x \neq 0$. Differentiating (C15) with respect to $x$, we obtain:

$$
G_{x}=\frac{-n a(1-\pi(k))}{(1+x)^{2}}+\frac{2 \pi^{\prime}(k)(1+x(1-a))}{a} .
$$

We can immediately see that $G_{x}<0$ meaning that (C16) implicitly defines $x=x(k)$. Hence, an optimal allocation is a solution $k^{*}>0$ to Equation (C14) with $x^{*}=x\left(k^{*}\right)$.

From (C13), we also have $\alpha k^{\alpha-1}>n \Gamma(x(k), k)$, where $\Gamma(x(k), k) \geqslant \pi(k)>\pi(+\infty)$. Therefore, there exists $\bar{k}>0$ defined by $\alpha \bar{k}^{\alpha-1}=n \Gamma(x(\bar{k}), \bar{k})$ such that $\alpha k^{\alpha-1}>n \Gamma(x, k)$ for all $k<\bar{k}$. Hence, $k^{*}$ belongs to $(0, \bar{k})$.

Let us note $L H S(k)$ the left-hand side and $R H S(k)$ the right-hand side of (C14), respectively. When $k$ tends to 0 , we deduce, using (C11), that $x(k)$ tends to 0 too. We get $R H S(0)=1 / a>0=\operatorname{LHS}(0)$. Moreover,

$$
\begin{aligned}
& \operatorname{LHS}(\bar{k})=\frac{(1-\alpha) \bar{k}^{\alpha}-(1-\pi(\bar{k})) x(\bar{k})}{(1+\delta)}\left[\frac{\delta}{\Gamma(x(\bar{k}), \bar{k})}+v\right]-n \bar{k}, \\
& \operatorname{RHS}(\bar{k})=\frac{(1+x(\bar{k}))^{2}}{a},
\end{aligned}
$$


with $(1-\alpha) \bar{k}^{\alpha}>(1-\pi(p(\bar{k}))) x(\bar{k})$. Since $\bar{k}$ has a bounded value and (C11) is satisfied, $x(\bar{k})$ is bounded above. This implies that $\operatorname{LHS}(\bar{k})>R H S(\bar{k})$ if $v$ is sufficiently large. Then, there exists a solution $k^{*} \in(0, \bar{k})$ to Equation (C14).

\section{C2 Unicity and second-order conditions}

Let us consider that $\pi(k)=\pi$ is constant, that is $\epsilon_{\pi}=0$. Since $x>0$, the social planner solves

$$
\begin{cases}\max _{c^{F}, c^{I}, d^{F}, d^{I}, x, k} & \pi\left(\ln c^{F}+\delta \ln d^{F}+v\right)+(1-\pi)\left(\ln c^{I}+\delta \ln d^{I}+\frac{a x}{1+x} v\right), \\ \text { s.t. } & k^{\alpha}=\pi c^{F}+(1-\pi)\left(c^{I}+x\right)+\frac{\pi d^{F}+(1-\pi) d^{I}}{n \Gamma(x)}+n k \Gamma(x),\end{cases}
$$

with $\Gamma(x) \equiv \pi+(1-\pi) \frac{a x}{1+x}$. Maximizing this objective function is equivalent to maximize

$$
\ln \left(c^{F}\right)^{\pi}\left(c^{I}\right)^{1-\pi}+\delta \ln \left(d^{F}\right)^{\pi}\left(d^{I}\right)^{1-\pi}+(1-\pi) \frac{a x}{1+x} v .
$$

This program can be solved in two steps. In a second step, we maximise $\ln C=\ln \left(c^{F}\right)^{\pi}\left(c^{I}\right)^{1-\pi}$ under the constraint $\pi c^{F}+(1-\pi) c^{I}=P^{c} C$ with respect to $c^{F}$ and $c^{I}$, taking the level of consumption expenditures $P^{c} C$ as given. We perform the same exercise for $\ln D=\ln \left(d^{F}\right)^{\pi}\left(d^{I}\right)^{1-\pi}$ under the constraint $\pi d^{F}+(1-\pi) d^{I}=P^{d} D$ with respect to $d^{F}$ and $d^{I}$, taking the level of consumption expenditures $P^{d} D$ as given. Using the first order conditions, we deduce that $P^{c}=1$ and $P^{d}=1$.

Therefore, in a first step, we have to solve:

$$
\begin{cases}\max _{C, D, x, k}, & \ln C+\delta \ln D+(1-\pi) \frac{a x}{1+x} v \\ \text { s.t. }, & k^{\alpha}=C+\frac{D}{n \Gamma(x)}+(1-\pi) x+n k \Gamma(x) .\end{cases}
$$

Note that this program above, using the constraint, can be rewritten $\max _{D, x, k} V$, with

$$
V \equiv \ln \left[k^{\alpha}-\frac{D}{n \Gamma(x)}-(1-\pi) x-n k \Gamma(x)\right]+\delta \ln D+(1-\pi) \frac{a x}{1+x} v,
$$

where $C=k^{\alpha}-\frac{D}{n \Gamma(x)}-(1-\pi) x-n k \Gamma(x)$. We can then derive the following first-order conditions: $:^{15}$

$$
\begin{gathered}
V_{D}=-\frac{1}{n \Gamma(x) C}+\frac{\delta}{D}=0, \\
V_{x}=\frac{D \Gamma^{\prime}(x) /\left[n \Gamma(x)^{2}\right]-(1-\pi)-n k \Gamma^{\prime}(x)}{C}+\frac{(1-\pi) a v}{(1+x)^{2}}=0,
\end{gathered}
$$

\footnotetext{
${ }^{15}$ In the following, we note $V_{u} \equiv \partial V / \partial u$ and $V_{u v} \equiv \partial^{2} V / \partial v \partial u$, with $\{u, v\}=\{D, x, k\}$.
} 


$$
V_{k}=\frac{\alpha k^{\alpha-1}-n \Gamma(x)}{C}=0 .
$$

We easily deduce that:

$$
\begin{gathered}
D=\delta n \Gamma(x) C, \\
D \Gamma^{\prime}(x) /\left[n \Gamma(x)^{2}\right]-(1-\pi)-n k \Gamma^{\prime}(x)=-C \frac{(1-\pi) a v}{(1+x)^{2}}, \\
\alpha k^{\alpha-1}=n \Gamma(x) .
\end{gathered}
$$

Establishing the second-order conditions for this last program gives us the second order conditions for the program (C17). Hence, we differentiate (C19)-(C21) and use (C22)-(C24), $\Gamma^{\prime}(x)=(1-\pi) \frac{a}{(1+x)^{2}}$ and $\Gamma^{\prime \prime}(x)=-2(1-\pi) \frac{a}{(1+x)^{3}}$ to compute the following Hessian matrix:

$$
H \equiv\left[\begin{array}{ccc}
V_{D D} & V_{D x} & V_{D k} \\
V_{x D} & V_{x x} & V_{x k} \\
V_{k D} & V_{k x} & V_{k k}
\end{array}\right]
$$

with

$$
\begin{gathered}
V_{D D}=-\frac{1+\delta}{n^{2} \Gamma(x)^{2} C^{2} \delta}<0, \\
V_{D x}=\frac{\Gamma^{\prime}(x)}{n C \Gamma(x)^{2}}[1-\Gamma(x) v]=V_{x D}, \\
V_{D k}=0=V_{k D}, \\
V_{x x}=-\frac{2(1-\pi)}{C(1+x)}-\frac{2 \delta \Gamma^{\prime}(x)^{2}}{\Gamma(x)^{2}}-\Gamma^{\prime}(x)^{2} v^{2}<0, \\
V_{x k}=-\frac{n \Gamma^{\prime}(x)}{C}=V_{k x}, \\
V_{k k}=\frac{(\alpha-1) n \Gamma(x)}{C k}<0 .
\end{gathered}
$$

To prove that an optimal allocation is a maximum, we have to show that $\mathcal{H}_{1} \equiv V_{D D}<0, \mathcal{H}_{2} \equiv V_{D D} V_{x x}-V_{D x} V_{x D}>0$, and $\mathcal{H}_{3} \equiv \operatorname{det} H<0$.

$\mathcal{H}_{1}<0$ is obvious. Let us now determine the sign of $\mathcal{H}_{2}$. Using (C25), (C26), and (C28), we get:

$$
\begin{aligned}
\mathcal{H}_{2} n^{2} C^{2} \Gamma(x)^{4}= & \frac{1+\delta}{\delta} \Gamma(x)^{2} \frac{2(1-\pi)}{C(1+x)}+2 \Gamma^{\prime}(x)^{2} \delta \\
& +2 \Gamma(x) \Gamma^{\prime}(x)^{2} v+\Gamma^{\prime}(x)^{2}\left[\frac{1+\delta}{\delta}-\Gamma(x)^{2}\right] v^{2}
\end{aligned}
$$


We observe that $\mathcal{H}_{2}>0$ because $\Gamma(x) \leqslant 1$. Finally, let us investigate the properties of $\mathcal{H}_{3}$. Using (C27), we have $\mathcal{H}_{3}=V_{D D} V_{x x} V_{k k}-V_{x D}^{2} V_{k k}-V_{x k}^{2} V_{D D}$. Then, using (C25), (C26), and (C28)-(C30), we obtain after some computations:

$$
\begin{aligned}
\mathcal{H}_{3} n^{2} C^{3} k \Gamma(x)^{4}= & -n \Gamma(x)^{2} \frac{1+\delta}{\delta} \frac{1-\pi}{C}\left[\frac{2(1-\alpha) \Gamma(x)}{1+x}+\Gamma^{\prime}(x)\right] \\
& -n \Gamma^{\prime}(x)^{2} \Gamma(x)[1-\alpha+\delta(1-2 \alpha)] \\
& -n \Gamma^{\prime}(x)^{2} \Gamma(x)^{2}\left[1-2 \alpha-\frac{1}{\delta}\right] v-\frac{(1-\alpha) n \Gamma^{\prime}(x)^{2} \Gamma(x)^{3}}{\delta} v^{2} .
\end{aligned}
$$

We deduce that $\mathcal{H}_{3}<0$ if $v$ is sufficiently large.

By a continuity argument, our result still holds if $\pi$ weakly depends on $k$, that is $\epsilon_{\pi}$ is close to 0 . Therefore, any optimal allocation is a maximum if $v$ sufficiently large and $\epsilon_{\pi}$ close to 0 . Note also that since this last result holds for any optimal allocation, such an allocation is unique.

\section{APPENDIX D: UTILITARIAN SOCIAL OPTIMUM WITH A NONSEPARABLE UTILITY}

The utilitarian criterion, at the steady state, can now be rewritten as follows:

$$
\begin{aligned}
\mathcal{L}= & \pi(k)\left[U\left(c^{F}, v\right)+\delta u\left(d^{F}\right)\right]+(1-\pi(k))\left[q(x) U\left(c^{I}, v\right)+(1-q(x)) U\left(c^{I}, 0\right)+\delta u\left(d^{I}\right)\right] \\
& +\lambda\left[k^{\alpha}-\pi(k) c^{F}-(1-\pi(k))\left(c^{I}+x\right)-\frac{\pi(k) d^{F}+(1-\pi(k)) d^{I}}{n \Gamma(x, k)}-n k \Gamma(x, k)\right]+\mu x .
\end{aligned}
$$

We obtain the following first-order conditions about consumption choices:

$$
\begin{gathered}
\frac{\partial \mathcal{L}}{\partial c^{F}}=0 \Leftrightarrow U_{1}\left(c^{F}, v\right)=\lambda, \\
\frac{\partial \mathcal{L}}{\partial c^{I}}=0 \Leftrightarrow q(x) U_{1}\left(c^{I}, v\right)+(1-q(x)) U_{1}\left(c^{I}, 0\right)=\lambda, \\
\frac{\partial \mathcal{L}}{\partial d^{i}}=0 \Leftrightarrow \delta n \Gamma(x, k) u^{\prime}\left(d^{i}\right)=\lambda, \quad i=F, I .
\end{gathered}
$$

\section{APPENDIX E: PROOF OF PROPOSITION 3}

Each household maximises the utility (2) under the budget constraints (3)-(4). The first-order conditions and the budget constraints allow us to derive the stationary levels of consumption, saving for both types of household and health expenditure

$$
\begin{gathered}
c^{F}=\frac{1}{1+\delta}\left(w+T^{F}-\frac{\theta}{R}\right), \\
d^{F}=\frac{R \delta}{1+\delta}\left(w+T^{F}-\frac{\theta}{R}\right), \\
s^{F}=\frac{\delta}{1+\delta}\left(w+T^{F}\right)+\frac{\theta}{R(1+\delta)},
\end{gathered}
$$


and

$$
\begin{gathered}
c^{I}=\frac{1}{1+\delta}\left[w+T^{I}-\frac{\theta}{R}-(1-\sigma) x\right], \\
d^{I}=\frac{R \delta}{1+\delta}\left[w+T^{I}-\frac{\theta}{R}-(1-\sigma) x\right], \\
s^{I}=\frac{\delta}{1+\delta}\left[w+T^{I}-(1-\sigma) x\right]+\frac{\theta}{R(1+\delta)}, \\
(1+x)^{2}=\frac{a v}{(1-\sigma) \delta}\left(s^{I}-\frac{\theta}{R}\right) .
\end{gathered}
$$

Finally, the government that perceives the taxes balances its budget at each period of time. Taking into account the population size, this means that ${ }^{16}$

$$
\frac{\theta}{n \Gamma}+\rho \alpha k^{\alpha}=\pi T^{F}+(1-\pi) T^{I}+\sigma(1-\pi) x
$$

Using the previous section, we recall that an optimal allocation is characterised by Equations (21), (C9), (C10), and (C11).

We are now able to derive the appropriate policy design that allows for decentralising the stationary optimal allocation. Using (E1), (E2), (E4), and (E5), the condition (21) is, partly, satisfied for

$$
T^{F}=T^{I}-(1-\sigma) x^{*}
$$

Obviously, we can set $T^{F}$ to zero and thus, $T^{I}=(1-\sigma) x^{*}$. Then, the heterogeneity in consumption among the two types of household is eliminated.

Comparing (21) with the FOCs of the decentralized economy, we should have that $R=(1-\rho) \alpha k^{\alpha-1}=n \Gamma(x, k)$, that is

$$
\rho=1-\frac{n \Gamma\left(x^{*}, k^{*}\right)}{\alpha\left(k^{*}\right)^{1-\alpha}} \in(0,1)
$$

Using (C10), we obtain

$$
-\frac{\sigma}{1-\sigma}=\frac{1}{v}\left(\frac{n k^{*}}{c^{*}}-\frac{\delta}{\Gamma\left(x^{*}, k^{*}\right)}\right) .
$$

It is straightforward that $\sigma<1$. As we have seen in the proof of Proposition $3, k^{*}$ has a finite value. Moreover, the consumption is bounded above, $c^{*}<\left(k^{*}\right)^{\alpha} /(1+\delta)$ and $\Gamma\left(x^{*}, k^{*}\right)>\pi(+\infty)$. We deduce that for $\delta$ low enough, we have $\sigma<0$.

Note that this last inequality requires that $n k^{*} \Gamma^{*}>\delta c^{*}$. Using the FOCs of the decentralized economy and the optimality condition (21), we deduce that $s^{F}=s^{I}=s^{*}$. Hence, the 
equilibrium on the capital market writes $n k^{*} \Gamma^{*}=s^{*}$. We deduce $s^{*}>\delta c^{*}$. Using (E1) and (E3), we obtain that $\theta>0$.

\section{APPENDIX F: PROOF OF PROPOSITION 4}

Let us begin by showing that $\xi^{E}<\pi\left(k^{E}\right)$. By using the egalitarian constraint and (28), we obtain

$$
\begin{aligned}
& \ln \left(\frac{\xi^{E}}{1-\xi^{E}} \frac{1-\pi\left(k^{E}\right)}{\pi\left(k^{E}\right)} c^{I E}\right)+\delta \ln \left(\frac{\xi^{E}}{1-\xi^{E}} \frac{1-\pi\left(k^{E}\right)}{\pi\left(k^{E}\right)} d^{I E}\right)+v=\ln c^{I E}+\delta \ln d^{I E}+\frac{a x^{E}}{1+x^{E}} v \\
& \Leftrightarrow(1+\delta) \ln \left(\frac{\xi^{E}}{1-\xi^{E}} \frac{1-\pi\left(k^{E}\right)}{\pi\left(k^{E}\right)}\right)=\left(\frac{a x^{E}}{1+x^{E}}-1\right) v,
\end{aligned}
$$

which is negative. Consequently, $\frac{\xi^{E}}{1-\xi^{E}} \frac{1-\pi\left(k^{E}\right)}{\pi\left(k^{E}\right)}<1$ and thus $\xi^{E}<\pi\left(k^{E}\right)$.

Now, we turn to Proposition 4. Using (22) and (23), an optimal utilitarian allocation is defined by the following two equations:

$$
\begin{aligned}
& H(x, k) \equiv(1-\pi(k))\left[\frac{a v}{(1+x)^{2}}+\frac{a \delta}{\Gamma(x, k)(1+x)^{2}}-\frac{a n k}{c(x, k)(1+x)^{2}}-\frac{1}{c(x, k)}\right]=0, \\
& J(x, k) \equiv \frac{1}{c(x, k)}\left[\alpha k^{\alpha-1}-n \Gamma(x, k)\right]+\pi^{\prime}(k)\left(1-\frac{a x}{1+x}\right)\left[v-\frac{n k}{c(x, k)}+\frac{\delta}{\Gamma(x, k)}\right]+\frac{\pi^{\prime}(k) x}{c(x, k)}=0,
\end{aligned}
$$

whereas using (29) and (30), the egalitarian ex-ante criterion satisfies:

$$
\begin{aligned}
H^{E}(x, k) \equiv & (1-\xi)\left[\frac{a v}{(1+x)^{2}}+\frac{a \delta}{\Gamma(x, k)(1+x)^{2}} \frac{1-\pi(k)}{1-\xi}-\frac{a n k}{c^{I}(x, k)(1+x)^{2}}-\frac{1}{c^{I}(x, k)}\right]=0, \\
J^{E}(x, k) \equiv & \frac{1}{c^{I}(x, k)}\left[\alpha k^{\alpha-1}-n \Gamma(x, k)\right]+\pi^{\prime}(k)\left(1-\frac{a x}{1+x}\right)\left[-\frac{n k}{c^{I}(x, k)}+\frac{\delta}{\Gamma(x, k)}\left(\frac{1-\pi(k)}{1-\xi}\right)\right] \\
& +\frac{\pi^{\prime}(k) x}{c^{I}(x, k)}-\pi^{\prime}(k)(1+\delta)\left(\frac{\xi}{1-\xi} \frac{1-\pi(k)}{\pi(k)}-1\right)=0,
\end{aligned}
$$

where using (27), the constraint on the good market and (C12), we have $c^{I E}=\frac{1-\xi^{E}}{1-\pi(k)} c(x, k) \equiv c^{I}(x, k)$.

Let us consider that $\pi$ is constant, thus $J(x, k)=0$ and $J^{E}(x, k)=0$ are both equivalent to $\alpha k^{\alpha-1}=n \Gamma(x)$, with $\Gamma(x)=\pi+(1-\pi) \frac{a x}{(1+x)}$. We deduce a negative relationship $k(x)$ between $k$ and $x$, that is $k^{\prime}(x)<0$. This still holds when $\pi$ weakly depends on $k$.

Before comparing $H(x, k)$ and $H^{E}(x, k)$, let us derive the following result. Substituting the expressions of the consumption in the equality $\ln c^{F E}+\delta \ln d^{F E}+v=\ln c^{I E}+\delta \ln d^{I E}+\frac{a x^{E}}{1+x^{E}} v$, we obtain

$$
(1+\delta) \ln \left[\frac{\xi^{E}}{1-\xi^{E}} \frac{1-\pi\left(k\left(x^{E}\right)\right)}{\pi\left(k\left(x^{E}\right)\right)}\right]=\left(\frac{a x^{E}}{1+x^{E}}-1\right) v .
$$


Since $\pi$ is decreasing in $k$ and $k$ decreasing in $x^{E}$, this equation defines a positive relationship between $x^{E}$ and $\xi^{E}$.

Now, using the expression of $c^{I}(x, k)$, we get:

$$
H^{E}(x, k) \equiv(1-\pi(k))\left[\frac{1-\xi^{E}}{(1-\pi(k))} \frac{a v}{(1+x)^{2}}+\frac{a \delta}{\Gamma(x, k)(1+x)^{2}}-\frac{a n k}{c(x, k)(1+x)^{2}}-\frac{1}{c(x, k)}\right]
$$

Since $\xi^{E}<\pi(k)$, we deduce that $H^{E}(x, k(x))>H(x, k(x))$ for all $x>0$. We also see that $H^{E}(x, k(x))$ is decreasing in $\xi^{E}$ and tends to $H(x, k(x))$ when $\xi^{E}$ tends to $\pi(k)$. Therefore, to be consistent with the fact that $x^{E}$ increases with respect to $\xi^{E}$, the unique solutions $x^{E}$ and $x^{*}$ solving respectively $H^{E}(x, k(x))=0$ and $H(x, k(x))=0$ are such that these two functions of $x$ are increasing in $x$. Therefore, we deduce that $x^{E}<x^{*}$. Since $k^{\prime}(x)<0$, we also have $k^{*}<k^{E}$.

Finally, at the optimum, $c^{I E}=\frac{1-\xi^{E}}{1-\pi\left(k^{E}\right)} c\left(x^{E}, k^{E}\right)>\frac{1-\xi^{E}}{1-\pi\left(k^{E}\right)} c\left(x^{*}, k^{*}\right)$ since $c(x, k)$ is an increasing function of $k$ and decreasing in $x$. So that, $c^{I E}>c\left(x^{*}, k^{*}\right)=c^{*}$.

\section{APPENDIX G: OPTIMAL POLICY IN THE CASE OF AN EX-ANTE EGALITARIAN CRITERION}

We are able to derive the appropriate policy design that allows for decentralising the stationary optimal allocation. Using (E1), (E2), (E4), and (E5), the egalitarian constraint is, partly, satisfied for

$$
\ln \left(w+T^{I E}-\frac{\theta}{R}-(1-\sigma) x^{E}\right)=\ln \left(w+T^{F E}-\frac{\theta}{R}\right)+\left(1-\frac{a x^{E}}{1+x^{E}}\right) \frac{v}{1+\delta} .
$$

As $c^{I E}>c^{F E}$, we have $T^{F E}<T^{I E}-(1-\sigma) x^{E}$. Obviously, we can set $T^{F E}$ to zero and thus

$$
T^{I E}=(1-\sigma) x^{E}+\left(w-\frac{\theta}{R}\right)\left(e^{\left(1-\frac{a x^{E}}{1+x^{E}}\right) \frac{v}{1+\delta}}-1\right)
$$

Comparing (27) with the FOCs of the decentralized economy, we should have that $R=(1-\rho) \alpha k^{\alpha-1}=n \Gamma(x, k)$, that is

$$
\rho^{E}=1-\frac{n \Gamma\left(x^{E}, k^{E}\right)}{\alpha\left(k^{E}\right)^{1-\alpha}} \in(0,1)
$$

Using (29), we obtain:

$$
1-\sigma^{E}=\frac{a v c^{I E}}{\left(1+x^{E}\right)^{2}} .
$$

Since $c^{I E}>c^{*}$ and $x^{E}<x^{*}$, we have $\sigma^{E}<\sigma^{*}<0$. 


\section{APPENDIX H: PROOF OF PROPOSITION 5}

First, let us show that $d^{I I P}>d^{F P}>d^{I F P}$ and $c^{I P}>c^{F P}$.

Using $\delta \ln d^{I F}+v=\delta \ln d^{I I}$, we have

$$
d^{I I P} / d^{I F P}=\exp \left(\frac{v}{\delta}\right)>1
$$

Using (32) and (H1), we deduce that

$$
d^{I F P}=\frac{\delta n \Gamma\left(x^{P}, k^{P}\right)}{\Psi\left(x^{P}, v\right)} c^{I P}
$$

with $\Psi(x, v) \equiv q(x)+(1-q(x)) \exp (v / \delta)>1$.

Substituting this expression and Equation (31) in the equality of utilities, we get

$$
c^{I P}=\Psi\left(x^{P}, v\right) \frac{\delta}{1+\delta} c^{F P}>c^{F P} .
$$

Note that using again (31) and (H3), we deduce that $d^{F P}=\Psi(x, v) \frac{1}{1+\delta} d^{I F P}>d^{I F P}$. Using (31) and (32), $c^{I P}>c^{F P}$ and $d^{F P}>d^{I F P}$, we also have $d^{F P}<d^{I I P}$.

Let us now turn to the Proposition 5. Substituting (31)-(H3) into (33), the choice of $x^{P}$ is given by

$$
\begin{aligned}
\frac{\mu^{P}}{\lambda^{P}\left(1-\pi\left(k^{P}\right)\right)}= & 1+\frac{a}{\left(1+x^{P}\right)^{2}}\left[n k^{P}-\left(\exp \left(\frac{v}{\delta}\right)-1\right) \Psi\left(x^{P}, v\right)^{-\frac{1}{1+\delta} \delta c^{F P}}\right. \\
& \left.-\frac{\delta}{\Gamma\left(x^{P}, k^{P}\right)}\left(\pi\left(k^{P}\right)+\left(1-\pi\left(k^{P}\right)\right) \Psi\left(x^{P}, v\right) \frac{\delta}{1+\delta}\right) c^{F P}\right]
\end{aligned}
$$

The resource constraint on the good market can also be rewritten

$$
c^{F P}\left[\pi\left(k^{P}\right)+\left(1-\pi\left(k^{P}\right)\right) \Psi\left(x^{P}, v\right)^{\frac{\delta}{1+\delta}}\right]=c\left(x^{P}, k^{P}\right),
$$

where $c\left(x^{P}, k^{P}\right)$ has a finite value. In addition,

$$
\begin{aligned}
\left(\exp \left(\frac{v}{\delta}\right)-1\right) \Psi\left(x^{P}, v\right)^{-\frac{1}{1+\delta} \delta c^{F P}} & =\frac{\delta c\left(x^{P}, k^{P}\right)\left(\exp \left(\frac{v}{\delta}\right)-1\right)}{\pi\left(k^{P}\right) \Psi\left(x^{P}, v\right)^{\frac{\delta}{1+\delta}}+\left(1-\pi\left(k^{P}\right)\right) \Psi\left(x^{P}, v\right)} \\
& <\frac{\delta c\left(x^{P}, k^{P}\right) \exp \left(\frac{v}{\delta}\right)}{\left(1-\pi\left(k^{P}\right)\right) \Psi\left(x^{P}, v\right)} \\
& <\frac{\delta c\left(x^{P}, k^{P}\right)}{\left(1-\pi\left(k^{P}\right)\right)\left(1-q\left(x^{P}\right)\right)} .
\end{aligned}
$$

This implies that 


$$
\begin{aligned}
& \left(\exp \left(\frac{v}{\delta}\right)-1\right) \Psi\left(x^{P}, v\right)^{-\frac{1}{1+\delta} \delta c^{F P}}+\frac{\delta c^{F P}}{\Gamma\left(x^{P}, k^{P}\right)}\left(\pi\left(k^{P}\right)+\left(1-\pi\left(k^{P}\right)\right) \Psi\left(x^{P}, v\right)^{\frac{\delta}{1+\delta}}\right) \\
& \quad<\frac{\delta c\left(x^{P}, k^{P}\right)}{\left(1-\pi\left(k^{P}\right)\right)\left(1-q\left(x^{P}\right)\right) \Gamma\left(x^{P}, k^{P}\right)} .
\end{aligned}
$$

We deduce that for $\delta$ low enough, $\mu^{P}>0$ and therefore $x^{P}=0$. Using Proposition 4 , $x^{*}>x^{E}>x^{P}$. When $\pi$ is constant, Equation (34) writes $\alpha k^{\alpha-1}=n \Gamma(x)$, where $\Gamma(x)=\pi+(1-\pi) \frac{a x}{(1+x)}$. This equality implicitly defines a negative relationship $k(x)$ between $k$ and $x$, that is $k^{\prime}(x)<0$. Since $\Gamma(x) \in(\pi(+\infty), 1)$, we also deduce that $k^{P}$ has a finite and strictly positive value. This still holds when $\pi$ weakly depends on $k$. We deduce $k^{*}<k^{E}<k^{P}$.

\section{APPENDIX I: OPTIMAL POLICY IN THE CASE OF AN EX-POST EGALITARIAN CRITERION}

We are able to derive the appropriate policy design that allows for decentralising the stationary optimal allocation. Recall that $x^{P}=0$, and thus $d^{I F}$ is not relevant anymore. Using (E1), (E2), (E4), and (E5), the only prevailing egalitarian constraint is satisfied for:

$$
\ln \left(w+T^{I P}-\frac{\theta}{R}\right)=\ln \left(w+T^{F P}-\frac{\theta}{R}\right)+\frac{v}{1+\delta} .
$$

We can set $T^{F P}$ to zero and thus

$$
T^{I P}=\left(w-\frac{\theta}{R}\right)\left(e^{\frac{v}{1+\delta}}-1\right)
$$

Comparing (27) with the FOCs of the decentralized economy, we should have that $R=(1-\rho) \alpha k^{\alpha-1}=n \Gamma(x, k)$, that is

$$
\rho^{P}=1-\frac{n \Gamma\left(0, k^{P}\right)}{\alpha\left(k^{P}\right)^{1-\alpha}} \in(0,1)
$$

Finally, since households choose $x=0$, we easily obtain

$$
1-\sigma^{P}=a v c^{I P} .
$$

Because $c^{I P}>c^{*}$ and $x^{*}>0$, we have $\sigma^{P}<\sigma^{*}<0$. 